Aristotle on Geometrical Potentialities

Naoya Iwata

Abstract: This paper examines Aristotle's discussion of the priority of actuality to potentiality in geometry at Metaphysics $\Theta 9,1051 \mathrm{a} 21-33$. Many scholars have assumed what I call the 'geometrical construction' interpretation, according to which his point here concerns the relation between an inquirer's thinking and a geometrical figure. In contrast, I will defend what I call the 'geometrical analysis' interpretation, according to which it concerns the asymmetrical relation between geometrical propositions in which one is proved by means of the other. His argument as so construed is ultimately based on the asymmetrical relation between the corresponding geometrical facts. Then I explore this ontological priority in geometry by drawing attention to the parallel passage Posterior Analytics II.11, 94a24-35, where Aristotle explains the relation between the same geometrical propositions in connection to material causation.

Keywords: Aristotle, potentiality, actuality, geometrical analysis, material causation

\title{
Introduction
}

In Metaphysics $\Theta 8$ Aristotle distinguishes different senses of “prior” ( $\pi \rho$ ó $\varepsilon \rho \circ \nu)$, such as prior in formula, time and substance, and argues that in each case actuality is prior to potentiality. He goes on to argue in the second half of the next chapter, $\Theta 9,1051 \mathrm{a} 21-33$, that the priority of actuality to potentiality also holds in the case of geometry. The key point of this argument is the claim that $\tau \grave{\alpha} \delta 1 \alpha \gamma \rho \alpha ́ \mu \mu \alpha \tau \alpha$ which exist potentially can be discovered by dividing them. Since dividing $\tau \grave{\alpha} \delta 1 \alpha \gamma \rho \alpha ́ \mu \mu \alpha \tau \alpha$ is concerned with the actuality which is prior (Met. $\Theta 9,1051 \mathrm{a} 21-23,29-30)$, it is important to know the meaning of dividing $\tau \grave{\alpha}$ $\delta ı \gamma \rho \alpha ́ \mu \mu \alpha \tau \alpha$ to understand how Aristotle establishes that actuality is prior to potentiality in the present geometrical case. 
It has widely been assumed in the literature that dividing $\tau \grave{\alpha} \delta \imath \alpha \gamma \rho \alpha ́ \mu \mu \alpha \tau \alpha$ means constructing geometrical figures or diagrams. ${ }^{1}$ I will call this traditional interpretation the 'geometrical construction' (GC) interpretation. According to the GC interpretation, when attempting to prove a geometrical proposition, one needs to recognize how to construct the relevant geometrical figure; the figure is initially in a potential state but is made actual by construction. The point is that, although the constructed figure (actuality) comes after the unconstructed one (potentiality), one’s actual cognition of the necessary construction precedes that potentiality. On this view, since this cognition is thus the prior actuality, which renders the potential construction actual, Aristotle thinks of the priority in question as a kind of epistemic priority. ${ }^{2}$

In this paper, in contrast, I advance what I call the 'geometrical analysis’ (GA) interpretation, according to which dividing $\tau \grave{\alpha} \delta 1 \alpha \gamma \rho \alpha ́ \mu \mu \alpha \tau \alpha$ means analyzing the geometrical proofs. When a geometrical proposition (conclusion to be proved) has not been proved, its proof exists potentially; but its proof is discovered or made actual by identifying the more basic proposition by means of which it is proved. This identification is what geometrical analysis consists in. The point of Aristotle's argument is therefore that, although a geometrical proposition which has not been proved yet (potentiality) comes before it is

\footnotetext{
${ }^{1}$ Julia Annas, Books M and N, 28-29; Z. Bechler, Aristotle’s Theory of Actuality, 168-69; Myles Burnyeat et al., Notes on Eta and Theta, 147; Jonathan Lear, “Aristotle’s Philosophy of Mathematics,” 179-80; Stephen Makin, Metaphysics Book $\Theta$, 237, 240-44; Marko Malink, “Aristotle on Principles as Elements,” 205-7; W. D. Ross, Aristotle’s Metaphysics, 2:268-69, 271-73; and J. Tricot, La Métaphysique, 2:521n2.

${ }^{2}$ Burnyeat et al. claim that the argument is for priority in substance (ov̉oía) (Notes on Eta and Theta, 147). But their point is that the potentiality in question is primarily the inquirer's capacity for cognition, from which the capacity of the object for being discovered secondarily derives. Accordingly, their view is not substantially different from the other GC interpreters' view that the argument is for a kind of epistemic priority. And they do not explain what their claim on priority in substance amounts to.
} 
proved (actuality), the proof of the more basic proposition precedes it. Thus, he is establishing the priority of actuality to potentiality by appealing to the asymmetric relation between geometrical propositions in which one proves one from the other.

If the GA interpretation is correct, Aristotle's argument here is concerned with a rather different kind of epistemic priority from the one the GC interpretation suggests: knowledge of a geometrical proposition is prior to that of one which derives from it. While the epistemic priority of the GC interpretation is based on the relation between an inquirer and a geometrical figure, that of the GA interpretation is on the relation between geometrical propositions themselves. A notable consequence of this aspect of the GA interpretation is that, since geometrical propositions are statements of the corresponding geometrical facts, his point about priority in $\Theta 9$ is linked to, or grounded in, the ontological order of geometrical facts. I shall therefore explore this ontological priority in geometry by looking at a parallel passage, Posterior Analytics II.11, 94a24-35, where he discusses the relation between the same geometrical facts, I argue, in connection to material causation.

Although the primary aim of the paper is a detailed exegesis of Metaphysics $\Theta 9$, 1051a21-33, its attention to the relevance of the passage to ontological priority in geometry has broader implications for Aristotle’s metaphysics and philosophy of mathematics, especially in terms of the following two points. First, given his view that geometrical objects do not change, how does he apply to them the potentiality-actuality schema that seems applicable to only those which can change? I shall pursue this question by considering the wider context of the second half of Metaphysics $\Theta$, where he extends his discussion of the potentiality-actuality relation beyond the domain of change, encompassing the mattersubstance relation (Met. $\Theta 6,1048 b 8-9$; cf. $\Theta 1,1045 b 35-1046 a 2, \Theta 3,1047 a 30-31)$. Second, there has been a growing interest among scholars in Aristotle’s discussion of priority in substance for considering whether ontological dependence is better described as existential or essentialist. Although this paper is not intended, of course, to settle that controversial debate, it will make an interesting addition by comparing ontological priority in geometry in $\Theta 9$ with priority in substance at $\Theta 8,1050 \mathrm{a} 4-\mathrm{b} 6$, the latter of which is one of the main passages for the debate. 
There is a problem I should notice before starting. Notoriously, Aristotle’s philosophy of mathematics is complicated, and there have been continuing interpretative disputes over the exact ontological status of his mathematical objects in relation to sensible ones. However, modern interpreters largely agree on the basic point that he considers mathematical objects to be real and instantiated in the physical world in some way, not simply the mathematician's mental construction. ${ }^{3}$ And the object of discussion in our passage is already geometrical objects or facts, which are assumed to exist at the outset. ${ }^{4}$ In this paper, therefore, I do not discuss the issue but simply suppose that genuine ontological relations could hold for geometrical facts themselves.

The structure of this paper is as follows. I first introduce Aristotle's two geometrical examples at Metaphysics $\Theta 9,1051 \mathrm{a} 21-33$ and then critically examine the GC interpretation of the passage (section 1). The next section is the central part of the paper, devoted to defending the GA interpretation and showing its implications for the ontological relation between geometrical facts (section 2). Then, I pursue this ontological priority in geometry by drawing attention to Aristotle's discussion of material causation in geometry at Posterior Analytics II.11, 94a24-35, and show that the relation between matter and substance is treated in the second half of Metaphysics Book $\Theta$ as relevant to objects that do not involve any

\footnotetext{
${ }^{3}$ For example, Ian Mueller thinks that mathematical (geometrical) objects for Aristotle are the physical objects whose irrelevant properties are all abstracted and which are then treated only as lines, planes and solids (intelligible matter), which in turn possess ordinary geometric properties like triangularity as their own essential attributes (“Aristotle on Geometrical Objects”). In contrast, Lear suggests that Aristotle allows physical objects themselves to possess as accurate properties of many more kinds as mathematics requires (“Aristotle’s Philosophy of Mathematics”). In addition, Phil Corkum attributes to Aristotle a weak version of fictionalism, not the view that mathematics treats what does not exist as if it exists, but the view that it treats what exists merely dependently as if it exists independently ("Aristotle on Mathematical Truth”).

${ }^{4}$ Burnyeat et al., Notes on Eta and Theta, 154.
} 
change, such as geometrical ones (section 3). Lastly, I conclude the paper by comparing the main points of ontological priority in geometry in $\Theta 9$ with his discussion of priority in substance in $\Theta 8$.

\section{The Geometrical Construction Interpretation}

At Metaphysics $\Theta 9,1051 \mathrm{a} 21-33$ Aristotle introduces two geometrical problems to provide an additional argument for his thesis that actuality is prior to potentiality. Let us first see how Aristotle presents the point. (I leave untranslated the key term $\tau \grave{\alpha} \delta ı \alpha \gamma \rho \alpha ́ \mu \mu \alpha \tau \alpha$.

$<\mathrm{ext}>$

And it is by actuality that $\tau \grave{\alpha} \delta 1 \alpha \gamma \rho \alpha ́ \mu \mu \alpha \tau \alpha$ are also discovered; for it is by division that people discover them. If they had been already divided, they would have been obvious; but as it is they are present only potentially.

[1] Why are the angles of the triangle equal to two right angles? Because the angles about one point are equal to two right angles. If, then, the line parallel to the side had been already drawn, it would have been evident to any one as soon as he saw the figure. [2] Why is the angle in a semicircle in all cases a right angle? Why, if three lines are equal—the two which form the base, and the one from the center-[the angle in the semicircle is] right is evident at a glance to one who knows the earlier proposition. ${ }^{5}$

Obviously, therefore, what is potential is discovered by being brought to actuality, the

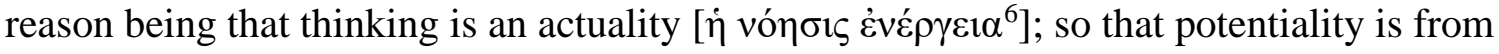

\footnotetext{
${ }^{5}$ The translation of this sentence is based on the textual suggestion made by P. S. Hasper, "Explanation."

${ }^{6}$ I adopt Ross's conjecture here (see Ross, Aristotle's Metaphysics, 2:272). The manuscript

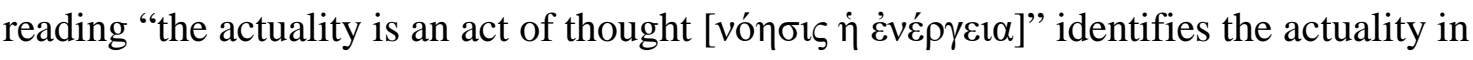
question, at 1051a31, with the preceding one at 1051a30. But this identification, as I shall
} 
actuality, and therefore it is by making that people acquire the knowledge, for the individual actuality is later in generation. (Met. $\Theta 9,1051 \mathrm{a} 21-33$, trans. modified $^{7}$ )

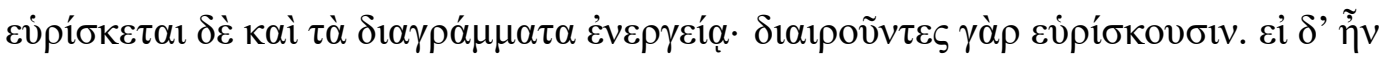

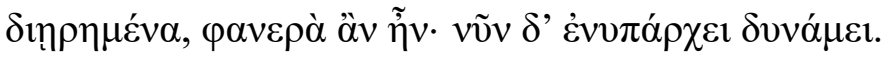

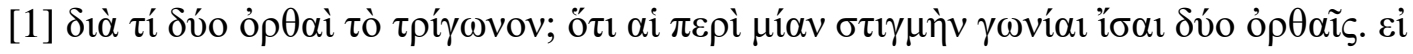

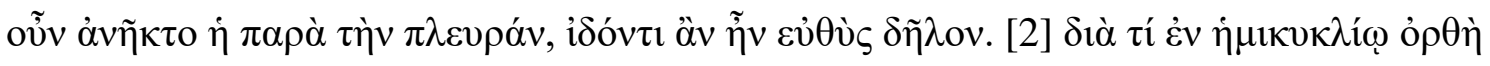

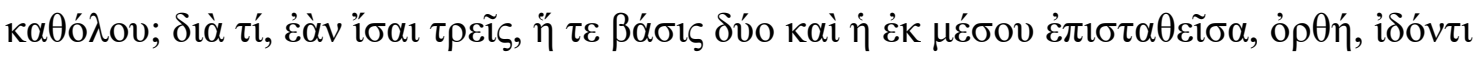

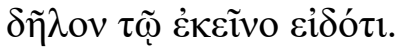

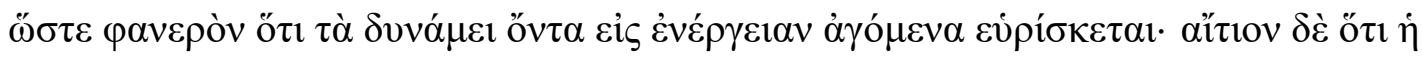

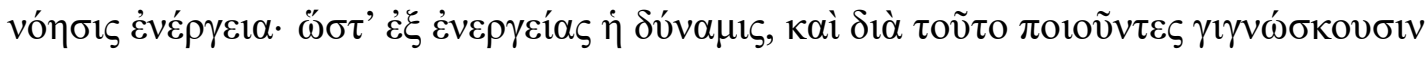

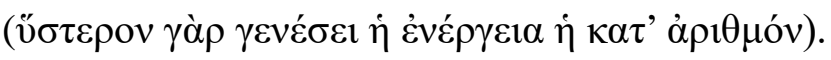

$</$ ext $>$

It is fairly clear what geometrical propositions Aristotle has in mind here: (1) that the triangle has the sum of its internal angles equal to two right angles; (2) that the angle in the semicircle is a right angle. There has been some scholarly dispute, on the other hand, as to the question of how to prove them, especially the latter proposition, due mainly to some textual difficulties of the passage. ${ }^{8}$ However, recent commentators have agreed on the basic procedure for the discuss below, is problematic for both GC interpretation and GA interpretation. See n. 15. ${ }^{7}$ All Aristotle translations are from Complete Works, edited by Jonathan Barnes. They are modified when necessary for clarity of the argument.

${ }^{8}$ For some recent scholars who defend the same proofs as I assume in this paper, see Burnyeat et al., Notes on Eta and Theta, 147-51; Hasper, "Explanation;” and Henry Mendell, “Two Geometrical Examples.” For those who endorse alternative proofs, on the other hand, see Thomas Heath, Mathematics in Aristotle, 27-30, 41-44, 71-74, 216-17; and Ross, Aristotle’s Metaphysics, 2:268-71. Makin conveniently surveys different possibilities (Metaphysics Book $\Theta$, 232-37). 
proofs, and adopting the alternative proofs does not affect my overall argument below against the GC interpretation in favor of the GA interpretation. In this paper, therefore, I simply assume the proofs defended in the recent literature, without discussing the textual issues, and focus on the question what philosophical point Aristotle is attempting to make.

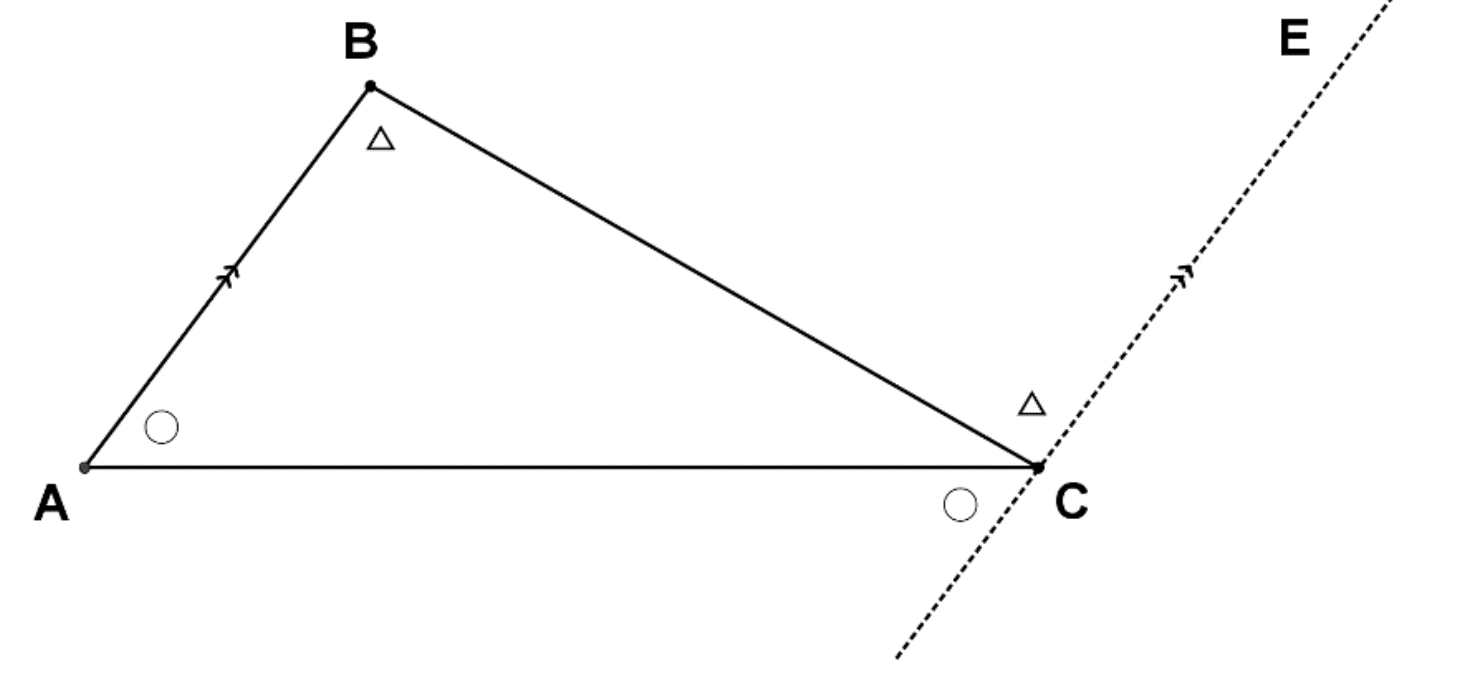

Fig. 1

D

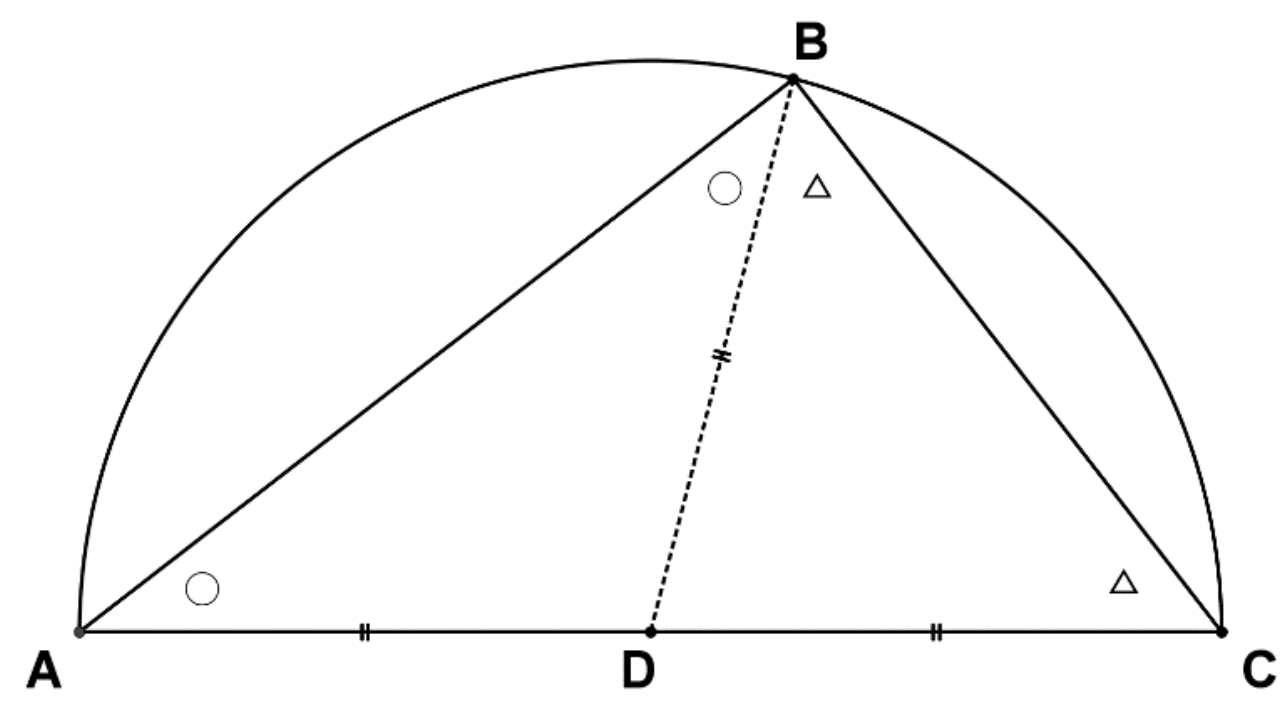

Fig. 2

The first example proves that the triangle $\mathrm{ABC}$ has the sum of its internal angles equal 
to two right angles (see fig. 1). Let the straight line DE parallel to AB be drawn through C. Then, the alternate angles $\mathrm{ABC}, \mathrm{BCE}$ are equal, and so are the alternate angles $\mathrm{BAC}, \mathrm{ACD}$ (Elements, I.29). Therefore, the sum of the internal angles ABC, BCA, CAB is equal to the sum of the angles BCE, BCA, ACD, that is, to two right angles. The second proves that the interior angle $\mathrm{B}$ of the triangle $\mathrm{ABC}$ inscribed in the given semicircle is a right angle (see fig. 2). Let a line be drawn from the center $\mathrm{D}$ to $\mathrm{B}$. Since $\mathrm{DB}$ is equal to DA, the angle DBA is equal to the angle DAB, and likewise the angle DBC is equal to the angle DCB (Elements, I.5). Since the triangle has just been proved to have the sum of its interior angles equal to two right angles, the interior angle $\mathrm{B}$ is equal to half of two right angles, that is, to a right angle.

A more difficult and important question for our purposes is what philosophical point, then, those geometrical problems are intended to make with regard to the potentialityactuality relation. Aristotle's primary objective here is to show that actuality is somehow prior to potentiality in the field of geometry as well. Many commentators basically assume the GC interpretation. ${ }^{9}$ On this view, the prior actuality in question is the exercise of an inquirer's ability to apprehend the geometrical construction necessary for a proof, which, in turn, renders the potential construction actual; the inquirer's actual thinking is thus prior to a potential construction. The details of the passage (Met. $\Theta 9,1051 \mathrm{a} 21-33$ ) are explained as

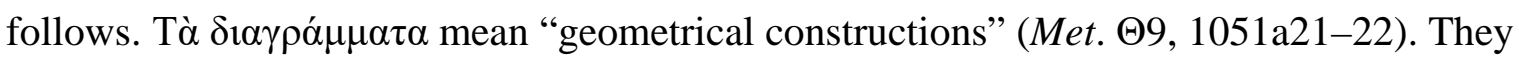

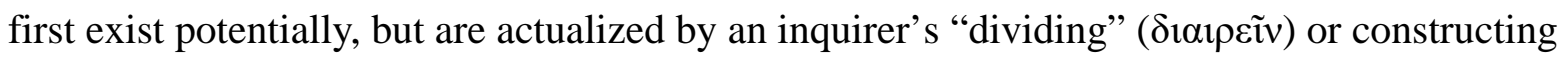
geometrical figures, namely drawing a line, joining points and so on (Met. $\Theta 9,1051 \mathrm{a} 22-24)$. For example, the first figure is divided or constructed by drawing the parallel line DE through the point $\mathrm{C}$, and the second by joining the points $\mathrm{D}, \mathrm{B}$; as a result of those actualizing processes, the geometrical proofs become clear (Met. $\Theta 9$, 1051a24-29). It then follows from this that the potentially existing constructions are discovered by being actualized (namely

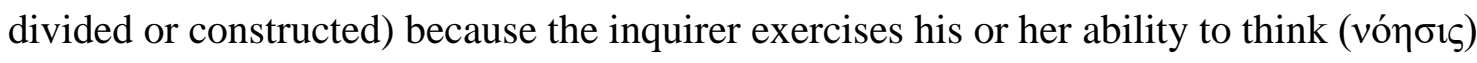

\footnotetext{
${ }^{9}$ For the list of scholars who endorse the GC interpretation, see n. 1. Among them, Makin, Metaphysics Book $\Theta$, 237, 240-44, and Ross, Aristotle’s Metaphysics, 2:268-69, 271-73, give a detailed reading of the passage, on which my presentation below is based.
} 
about the geometrical constructions (Met. $\Theta 9,1051$ a29-31). In geometry, therefore, actuality is epistemically prior to potentiality in the sense that an inquirer's actual thinking is prior to potential constructions, although actual constructions are posterior in generation to potential constructions (Met. $\Theta 9,1051 \mathrm{a} 31-33)$.

However, I strongly doubt that this is the right reading of the passage, for the following three reasons. First, it strikes me as rather unnatural to express the process of

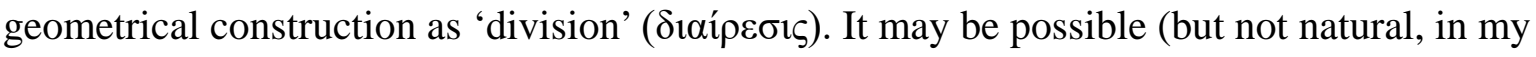
view) that in the second example Aristotle describes as division the process of joining the points $\mathrm{D}, \mathrm{B}$ because it divides the triangle $\mathrm{ABC}$ into two isosceles triangles $\mathrm{ABD}, \mathrm{CBD}$ (see fig. 2). But the same cannot be said of the first example because the construction there is effected by drawing an auxiliary line parallel to the opposite side, which is not dividing the given triangle at all but merely adding a line to it. ${ }^{10}$ Ross claims that this case is "to divide the space surrounding the triangle." ${ }^{11}$ But that is very awkward. Since Aristotle elsewhere uses

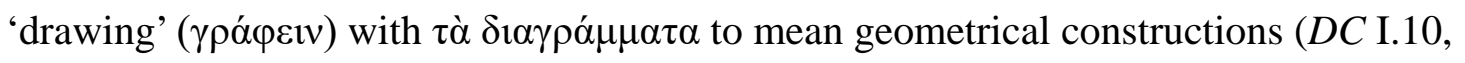
279b34), it would have been much more natural for him to use the same verb here than

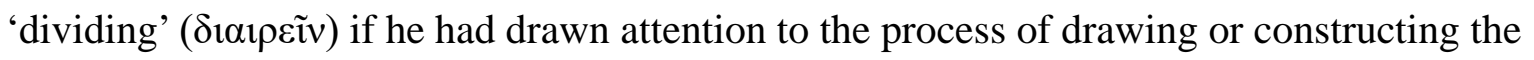
desired geometrical figures. The GC interpreters do not provide any other textual evidence for justifying their clumsy reading of 'division.' Some might object, however, that the present

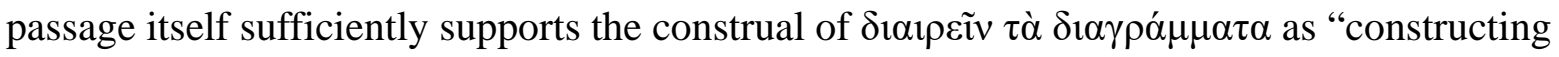
the geometrical figures.” For that reading appears to be suggested by the parallel between the sentence "If they [ $\tau \alpha \grave{\alpha} \delta 1 \alpha \gamma \rho \alpha ́ \mu \mu \alpha \tau \alpha]$ had been already divided, they would have been obvious

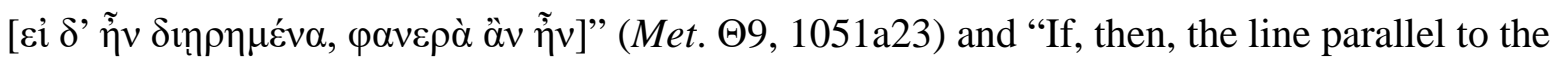
side had been already drawn, it would have been evident to any one as soon as he saw the

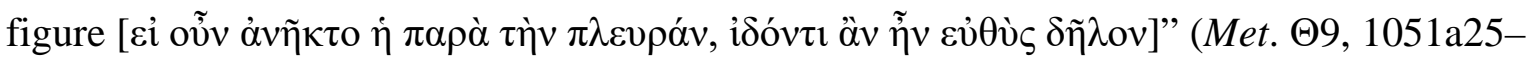

\footnotetext{
${ }^{10}$ My criticism here does not depend on the specific construction I assumed at the outset. Even if an alternative construction for the first example is adopted, it does not involve dividing the given triangle.

${ }^{11}$ Ross, Aristotle’s Metaphysics, 2:269.
} 
26). The idea is that, since the latter if-clause signifies the process of a geometrical construction, the former should signify the same. However, this reading, in turn, does not give a good account of the parallel between the apodoses. For it is grammatically clear that the subject of the former apodosis is $\tau \grave{\alpha} \delta 1 \alpha \gamma \rho \alpha ́ \mu \mu \alpha \tau \alpha$, which, according to the GC interpretation, are geometrical constructions; that of the latter, on the other hand, is the answer to the question of why the angles of the triangle are equal to two right angles (Met. $\Theta 9,1051 \mathrm{a} 24)$. The latter sentence therefore suggests that what would become clear as a result

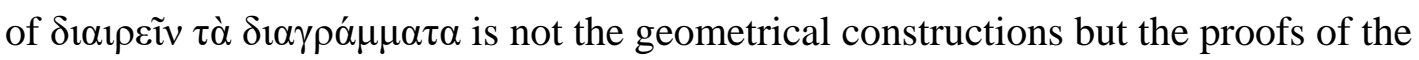
geometrical propositions. This consideration rather supports my claim below that $\tau \grave{\alpha}$ $\delta ı \alpha \gamma \rho \alpha \mu \mu \alpha \tau \alpha$ should be taken as the geometrical proofs, and that $\delta 1 \alpha \iota \varepsilon \tilde{v} v$ them is a process that identifies the premises by means of which the geometrical propositions are proved. We can thus think that Aristotle mentions the geometrical construction in the latter if-clause only insofar as it serves the purpose of revealing the structure of the relevant geometrical proof. If so, the geometrical construction itself is only of secondary significance for his present discussion, and cannot be the focus of the passage.

Second, the GC interpretation cannot explain why Aristotle had to introduce two geometrical examples rather than one. It is highly likely that the two examples presented in our passage are not independent of, but closely connected to, each other. The first proposition forms the basis for the proof of the second: the proposition that the angle in a semicircle is a right angle is proved by means of the proposition that the internal angles of the triangle are equal to two right angles. The dependence of the second on the first is particularly emphasized by the clause at 1051a27-29, "why ... [the angle in the semicircle is] right is

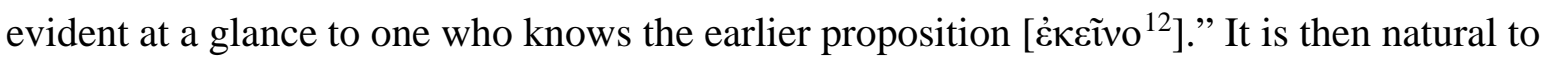
expect that the relation in question has some bearing on Aristotle's central argument about the

\footnotetext{
${ }^{12}$ If one adopts the Euclidian proof (Elements, III.31) for the second geometrical problem,

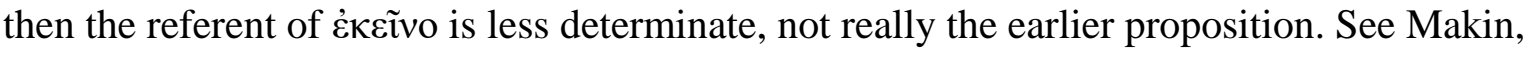
Metaphysics Book $\Theta$, 237. As far as I can see, however, no scholar who endorses the GC interpretation adopts this Euclidian proof.
} 
priority of actuality to potentiality. However, the GC interpretation makes no use of this point. For the three-fold division it makes-a potential construction, an actual construction and an inquirer's actual thinking-is something applied to each of the two geometrical examples separately. There is no element in it that requires the connection between the two geometrical examples. If the GC interpretation is correct, then Aristotle could have made his point simply by taking up one geometrical construction or unrelated two constructions for discussion, or rather he should have done so to avoid misunderstanding.

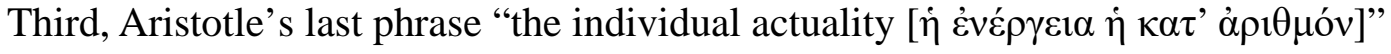
(Met. $\Theta 9,1051 \mathrm{a} 32-33$ ) hardly matches the contrast the GC interpreters make between the two kinds of actuality. The phrase is literally translated as "the actuality in terms of number" and indicates that the actuality in question, which is posterior, is numerically different from the actuality contrasted, which is prior. The point of the GC interpretation is that the contrast is between an inquirer's actual thinking and the actual geometrical constructions: while the latter are posterior in generation to the potential constructions, the former is epistemically prior to them. ${ }^{13}$ But it is difficult to see how those two actualities are numerically different from each other. For the GC interpreters also notice that the divisions or geometrical constructions in question are effected in thought, not done to geometrical objects themselves, because Aristotle does not consider geometrical objects to be susceptible to any temporal process or change (cf. DC I.10, 279b32-280a11). ${ }^{14}$ If so, when an inquirer has exercised his or her ability to think about constructions and figured out the constructions necessary for

\footnotetext{
${ }^{13}$ Makin, who is one of the GC interpreters, claims that it is preferable to construe that, while actual constructions are posterior in generation, they are prior epistemically (Metaphysics Book $\Theta, 242-43)$. This claim clearly reveals the idea that actual constructions are identical to an inquirer's actual thinking. But if so, as I am arguing here, his construal hardly fits with Aristotle's use of "the individual actuality" at 1051a32-33, which suggests that the contrast is made between two different items.

${ }^{14}$ See Makin, Metaphysics Book $\Theta$, 237, 239, 242-44; and Ross, Aristotle’s Metaphysics, 2:269.
} 
proofs, has not he or she thereby effected or actualized them in thought at the same time? The distinction between the inquirer's actual thinking about constructions and the actual constructions would be plausible only if the latter were something that is produced outside the inquirer's mind. ${ }^{15}$ It is helpful to see how Aristotle a little earlier uses an expression

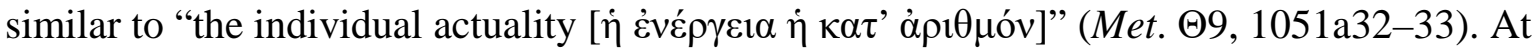
$\Theta 8,1049 \mathrm{~b} 18-19$, where he discusses priority in time, he says, "what is actual, which is the

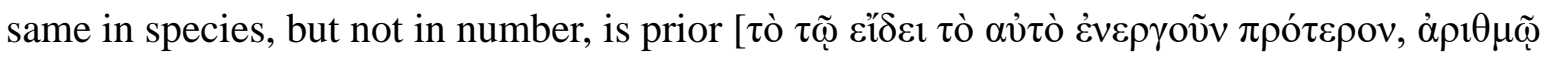
$\delta$ ' ov́].” An example of this case is that, while an individual man's actuality is temporally posterior to his potentiality (the matter), his father's actuality is temporally prior to that potentiality. We can naturally understand about it that the individual man is numerically different from his father. On the other hand, the distinction between the two actualities the GC interpreters allege-an inquirer's actual thinking and actual geometrical constructionsis so unclear that it cannot properly capture the sense of "the individual actuality" at 1051a32-33.

The discussion so far shows that the GC interpretation leaves a lot to be desired. In the next section I shall develop the GA interpretation, and show how it can resolve the above

${ }^{15}$ Ross proposes the alternative reading of 1051a30-31 “the geometer's thinking is an

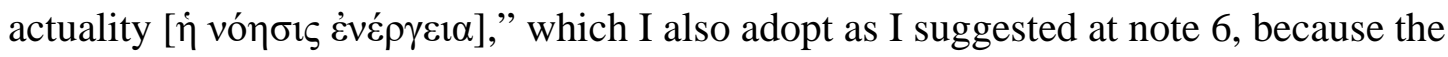

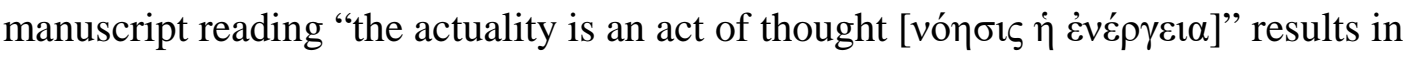
identifying the actuality of thought at 1051a30-31 with the actuality at 1051a30, which according to the GC interpretation is the actual construction (Aristotle's Metaphysics, 2:27273). Although my GA interpretation does not take the actuality at 1051a30 to mean the actual construction, I do agree with Ross that there is a problem with Aristotle's overall argument if we read him as identifying the two actualities here. But my contention against the GC interpretation is that as long as an inquirer's actual thinking, as Ross claims, is his or her apprehension of the construction, it is still unclear how it can be numerically different from the actual construction which is also something made in thought. He leaves the difference unexplained. 
issues the GC interpretation faces.

\section{The Geometrical Analysis Interpretation}

Here is the gist of my GA interpretation. I take $\tau \grave{\alpha} \delta 1 \alpha \gamma \rho \alpha ́ \mu \mu \alpha \tau \alpha$ to mean the "geometrical proofs." To say "the geometrical proofs exist only potentially" is to say that the corresponding geometrical propositions (conclusions to be proved) have not been proved. A geometrical proposition or its proof therefore exists actually if it has already been proved. But the proof of a geometrical proposition is discovered by identifying the prior proposition by means of which that proposition is proved. This regressive process, a process that deliberates from what premise(s) a given proposition is derived, is what Aristotle calls 'division,' which

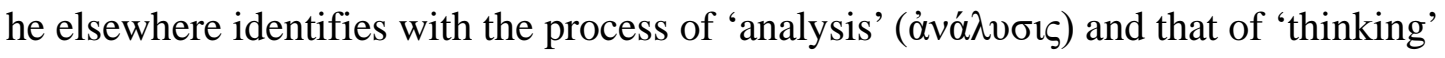

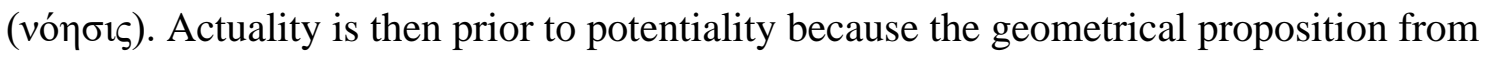
which a given proposition is derived has already been proved. By “making” ( $\pi$ oıoṽv $\tau \varepsilon \varsigma$ ) or producing a synthetic proof from that prior proposition, therefore, an inquirer acquires knowledge of the given proposition, whose actuality is posterior to its potentiality. In this section I shall explain those points one by one.

The Greek word $\delta i \alpha ́ \gamma \rho \alpha \mu \mu \alpha$ occurs in the whole Aristotelian corpus 13 times, out of which it occurs in our passage once and in a continuous passage 4 times, so we can find its use in 9 other places. ${ }^{16} \mathrm{~A}$ survey of the usage shows that there is a marked tendency in Aristotle to use the word in connection with geometrical proofs rather than with geometrical constructions. ${ }^{17}$ As far as I can see, DC I.10, 279b32-280a11 and Metr. III.5, 375b18 are the

${ }^{16}$ Cat. 12, 14b1; APr I.24, 41b14; SE 16, 175a27; DC I.10, 279b32-280a11 (4 occurrences); Metr. III.5, 375b18; Met. B3, 998a25, Г3, 1014a36; EN III.3, 1112b21; and Pol. V.12, $1316 a 7$.

${ }^{17}$ Cf. Heath, Mathematics in Aristotle, 216; Wilbur Richard Knorr, The Evolution of the Euclidean Elements, 69-74; and Reviel Netz, The Shaping of Deduction, 35-38. 
only places where Aristotle may be drawing some attention to the aspect of constructing a geometrical figure, but even there his purpose is to demonstrate a fact clearly by means of the construction. ${ }^{18}$ (Pol. V.12, 1316a7 is related only to a geometrical figure, not to its construction.) The majority of the occurrences, on the other hand, explicitly focus on the proofs of geometrical propositions: some (Cat. 12, 14b1; APr I.24, 41b14; Met. B3, 998a25, ${ }^{19}$ $\Gamma 3,1014 \mathrm{a} 36)$ are directly connected with geometrical proofs, and the others (SE 16, 175a27; EN III.3, 1112b21) are indirectly so because they are in the context of geometrical analysis, which is, as I shall discuss below, a method for discovering a proof.

The above statistical observation indicates that Aristotle tends to use $\tau \grave{\alpha} \delta 1 \alpha \gamma \rho \alpha ́ \mu \mu \alpha \tau \alpha$ primarily in the sense of geometrical proofs. And the view that by $\tau \grave{\alpha} \delta 1 \alpha \gamma \rho \alpha ́ \mu \mu \alpha \tau \alpha$ he means the same in our present passage is strongly supported by one of the aforementioned passages,

${ }^{18}$ The point at Metr. III.5, $375 \mathrm{~b} 18$ is to make the truth of a fact obvious by constructing a

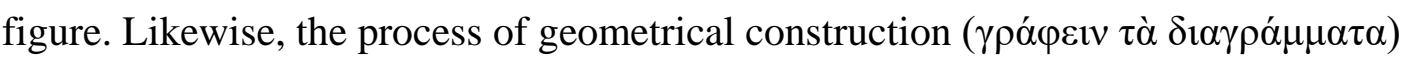
mentioned at DC I.10, 279b32-280a11 is said to be useful for the purpose of instruction (280a3). See Top. VIII.3, 158b30, where $\gamma \rho \alpha \dot{\alpha} \varphi \varepsilon \sigma \theta \alpha$ is used to mean "prove.” Cf. Knorr, The Evolution of the Euclidean Elements, 70, 72.

${ }^{19}$ Here Aristotle says, “we give the name of 'elements' to those geometrical propositions, the proofs of which are implied in the proofs of the others, either of all or of most $[\tau \tilde{\omega} v$

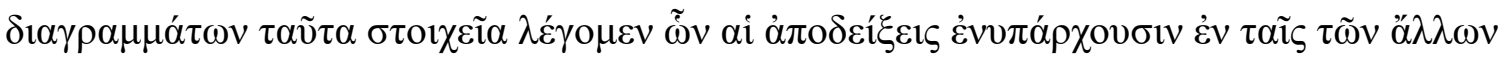

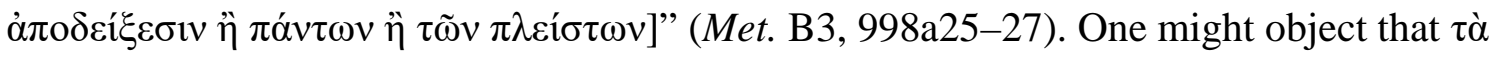
$\delta 1 \alpha \gamma \rho \alpha ́ \mu \mu \alpha \tau \alpha$ are treated here as "geometrical theorems" rather than "geometrical proofs" because he is speaking of the "proofs" of $\tau \grave{\alpha} \delta 1 \alpha \gamma \rho \alpha ́ \mu \mu \alpha \tau \alpha$. But we cannot easily conclude about this passage that $\tau \grave{\alpha} \delta 1 \alpha \gamma \rho \alpha ́ \mu \mu \alpha \tau \alpha$ are identical with theorems, excluding their proofs. For he makes exactly the same point at Metaphysics $\Delta 3$, 1014a35-37, as we will see just below, by saying that the elements of $\tau \grave{\alpha} \delta 1 \alpha \gamma \rho \alpha ́ \mu \mu \alpha \tau \alpha$ are implied in most of $\tau \grave{\alpha} \delta 1 \alpha \gamma \rho \alpha ́ \mu \mu \alpha \tau \alpha$, which he describes as a species of demonstrations ( $\dot{\alpha} \pi$ o $\delta \varepsilon \dot{\xi} \xi \varepsilon 1 \varsigma)$. The point of saying "the proofs of $\tau \grave{\alpha} \delta ı \gamma \rho \alpha ́ \mu \mu \alpha \tau \alpha ”$ may simply be his emphasis on the aspect of the geometrical proofs. 


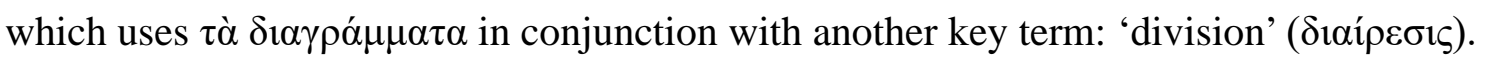

$<\mathrm{ext}>$

We call an element that which is the primary component immanent in a thing, and indivisible in kind into other kinds, e.g. the elements of speech are the parts of which speech consists and into which it is ultimately divided, while they are no longer divided into other forms of speech different in kind from them. If they are divided, their parts are of the same kind, as a part of water is water (while a part of the syllable is not a syllable). Similarly those who speak of the elements of bodies mean the things into which bodies are ultimately divided, while they are no longer divided into other things differing in kind; and whether the things of this sort are one or more, they call these elements. The elements of $\tau \grave{\alpha} \delta 1 \alpha \gamma \rho \alpha \dot{\alpha} \mu \alpha \alpha \alpha$, and in general the elements of demonstrations, have a similar character; for the primary demonstrations, which are immanent in most demonstrations, are called elements of demonstrations; and the primary syllogisms, which have three terms and proceed by means of one middle, are of this nature. (Met. $\Delta 3,1014 \mathrm{a} 26-\mathrm{b} 3$, trans. modified) $</$ ext $>$

This passage is the only other instance where Aristotle discusses division in the context of $\tau \grave{\alpha}$ $\delta 1 \alpha \gamma \rho \alpha ́ \mu \mu \alpha \tau \alpha$. It is true that he does not directly mention division in the specific discussion of $\tau \grave{\alpha} \delta 1 \alpha \gamma \rho \alpha ́ \mu \mu \alpha \tau \alpha$. But that the concept is relevant is implied by his claim on the similarity of the geometrical case to the other cases, where he says that, while composite objects can be divided into parts, elements can no longer be divided into smaller parts differing in kind. What should be emphasized first is that dividing $\tau \grave{\alpha} \delta 1 \alpha \gamma \rho \alpha ́ \mu \mu \alpha \tau \alpha$ clearly means the process of dividing them into their parts, whatever those parts may be, a process that appears to be radically different from the process of constructing geometrical figures by drawing a line, joining points and so on. Also, his remark that $\tau \grave{\alpha} \delta 1 \alpha \gamma \rho \alpha ́ \mu \mu \alpha \tau \alpha$ are a species of

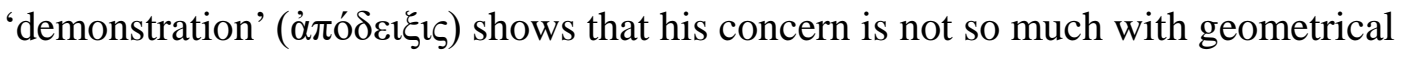
constructions as with geometrical proofs.

What are, then, the corresponding composite objects in the case of geometrical 
proofs? And what does Aristotle mean by 'dividing' them? He says that the elements of

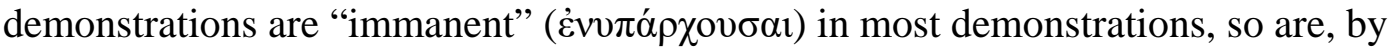
implication, the elements of geometrical proofs in most geometrical proofs. The idea is almost clear that a geometrical proof is composite in the sense that it is composed of a set of other geometrical propositions that have been proved beforehand. (Aristotle’s above wording must be elliptical because a geometrical proof, as a matter of fact, formerly includes only those other propositions or conclusions that have been proved, but not their proofs as well, which are given separately.) A more complex geometrical proof is composed of more geometrical propositions, and a simpler geometrical proof of fewer geometrical propositions. The smallest parts or elements of geometrical proofs are still considered here to be demonstrable, not the first principles of geometry, but those elementary propositions that can be proved only by first principles. ${ }^{20}$ Aristotle's general point should be that a system of geometry is structured in the way that more complex propositions are grounded in more basic propositions and ultimately the primary ones. From this we can reasonably suspect that dividing a geometrical proof may well mean distinguishing its constituents, namely clarifying by what more basic proposition(s) the geometrical proposition is proved.

This regressive conception of division is by no means special to the current passage in

${ }^{20}$ It should be noted that here the elements of geometrical propositions are not indemonstrable first principles, such as definitions, hypotheses and axioms, because the elements in question are treated as the first geometrical propositions among demonstrable ones (pace Tricot, La Métaphysique, 1:252n1). The same goes for Met. B3, 998a25-27, where Aristotle says, "we give the name of 'elements' to those geometrical propositions, the proofs of which are implied in the proofs of the others, either of all or of most” (my italics; cf. Hermann Bonitz, Index Aristotelicus, 702b45-50). In other places, however, the elements in geometry seem to mean indemonstrable first principles. See, for example, Cat. 12, 14a37-b1; Top. VIII.3, 158b35-159a2, and VIII.14, 163b17-28. There is apparently some imprecision in Aristotle's usage (see also the next paragraph). But what is at least clear is that he does not include indemonstrable first principles in $\tau \grave{\alpha} \delta ı \alpha \gamma \rho \alpha \mu \mu \alpha \tau \alpha$, which are our current concern. 
the corpus. Here Aristotle similarly supposes that complex syllogisms that have many middle terms are also ultimately divided or reduced to the primary ones that have only one middle term. We can see basically the same idea in the Posterior Analytics, although there Aristotle normally (but not always [APo II.18, 99b7]) treats as indivisible an immediate proposition that does not have a middle term between its terms. He says, for example, "By belonging or not belonging indivisibly [ $\dot{\alpha} \tau o ́ \mu \omega \varsigma]$ I mean that there is no middle term for them; for in this way their belonging or not belonging will no longer be in virtue of something else" (APo I.15, 79a34-36). ${ }^{21}$ The proposition that $B$ is $A$ is indivisible or immediate if it does not have a middle term $(C)$ that constitutes the set of syllogistic premises that $B$ is $C$, and that $C$ is $A$. $\mathrm{A}$

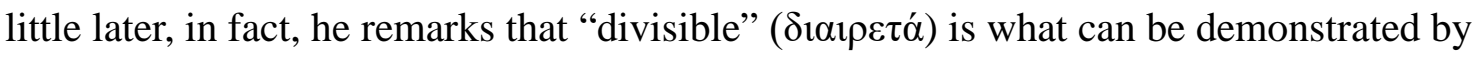

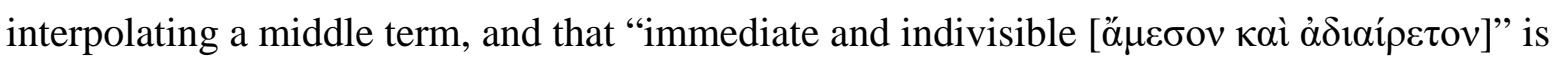
an indemonstrable first principle (APo I.22, 84a29-37; cf. I.23, 84b34-35). All these examples suggest that the process of division lies in grasping the middle term(s) by means of which a proposition can be proved. And we can find the best example of such a regressive use of division in a general form at the beginning of the Physics, where he says, "Now what is to us plain and clear at first is rather confused masses, the elements and principles of which

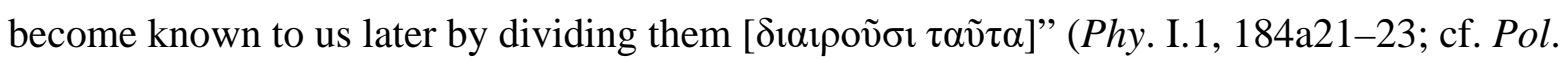
I.1, 1252a18-20).

It emerges from the discussion so far that Aristotle's regressive use of division is

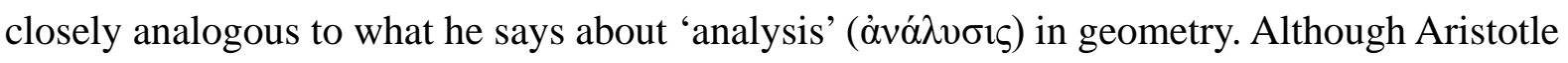
never devotes a substantial discussion to geometrical analysis, his basic idea about it is clear enough from Nicomachean Ethics III.3, 1112b11-24, where his discussion of analysis, importantly, appears in connection with the word $\delta$ á $\gamma \rho \alpha \mu \mu \alpha$, which we should translate also here as "a geometrical proof" because it is concerned with how to construct a deductive proof. He starts by saying that we deliberate not about ends but what contributes to them. For example, doctors do not deliberate whether they should cure patients, but only how they can cure them best. And he continues:

${ }^{21}$ Cf. APo I.15, 79b13, 21-22; I.16, 79b30, 80a3, 5, 12; and I.17, 80b17. 
$<\mathrm{ext}>$

if the end is achieved by one means only, they consider how it will be achieved by this and by what means this will be achieved, till they come to the first cause, which in the order of

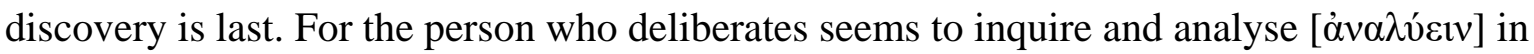
the way described as though he were analysing a geometrical proof (not all inquiry appears to be deliberation — for instance mathematical inquiries — but all deliberation is inquiry), and what is last in the order of analysis seems to be first in the order of generation. (EN III.3, 1112b17-24, trans. modified)

$</$ ext $>$

The passage indicates that geometrical analysis goes backwards from the assumption that a given proposition to be proved is true. An inquirer then considers from what prior proposition (with some other auxiliary ones when necessary) the given proposition is derived, from what still prior proposition that prior proposition is derived, and so on, until he or she reaches the

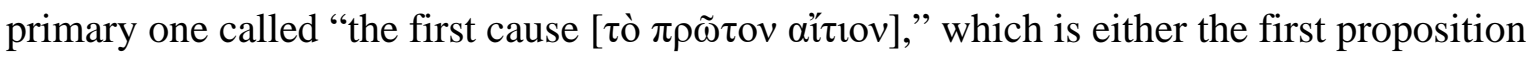
he or she can prove to be true independently of the initial assumption and the intermediate process, or the relevant indemonstrable first principle. ${ }^{22}$ Just as a doctor attempts to discover how to treat his or her patient by following the deliberative process from that end to its proximate means and ultimate one, an inquirer thus attempts to discover the proof of a geometrical proposition by following the analytic process from that proposition to its proximate premise and ultimate one. This heuristic process of analysis, therefore, is virtually

${ }^{22}$ APo I.12, 78a6-13 suggests that Aristotle considers this heuristic process of analysis, at least in the case of mathematics, to be deductive. The locus classicus on geometrical analysis is Pappus's “Treasury of Analysis,” where he gives a general description of the method (Collection, VII. 634, 3-636, 14). The point that the process of analysis is deductive in actual geometrical examples is clearly shown, for example, by Ali Behboud, “Greek Geometrical Analysis;” Norman Gulley, “Greek Geometrical Analysis;” Jaakko Hintikka and Unto Remes, The Method of Analysis; and Ken Saito and Nathan Sidoli, “The Function of Diorism.” 
the same as what we identified earlier as a regressive process of 'division.'

Aristotle also says that the end point of analysis is the starting point of generation

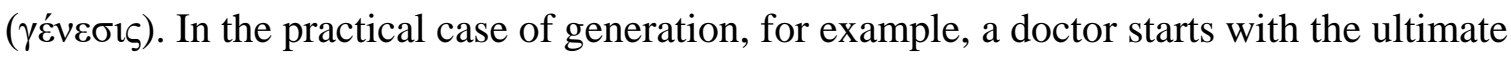
means (rubbing) to bring about its consequence (warmth in the body), which constitutes the proximate means to bring about the original end (health). (Of course, there can be many more steps in other cases.) One might wonder how the unchanging, logical process of geometrical proofs, on the other hand, is concerned with generation. But there seems to be a sense in which geometrical proofs can analogously be said to be a process of generation: the given proposition or conclusion deductively derives from its premises (cf. MA 7, 701a7-1323). After completing the above analytic process of identifying the ultimate premise from which a given proposition is derived, the inquirer goes on to the synthetic process of actually proving the proposition by employing the identified premises in order. It is therefore likely that by "the order of generation” in geometry Aristotle means the order of synthesis in which an inquirer starts with the ultimate premise he or she identified in the analytic process and deductively derives the given proposition from it in reverse order. This synthetic order corresponds to such a deductive structure of geometry as we find in Euclid's Elements, where all geometrical propositions ultimately derive from the few indemonstrable first principles in order.

Lastly, it is worth noticing that at Metaphysics Z7, 1032b15-17 Aristotle calls the above pair of analysis and synthesis in the case of productive knowledge the process of

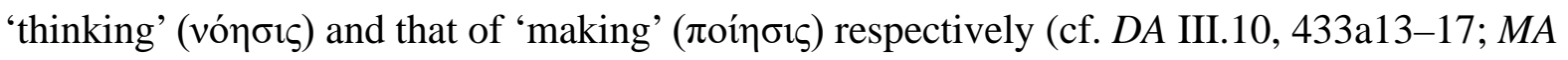
7, 701a7-13). There he says, "that which proceeds from the starting-point and the form is thinking, and that which proceeds from the final step of the thinking is making.” The process of thinking is an analytic one from a given end to its ultimate means, and the process of making is in turn a synthetic one from that ultimate means to the initial end. Although he does not mention the corresponding processes in geometry there, what is striking about it for our

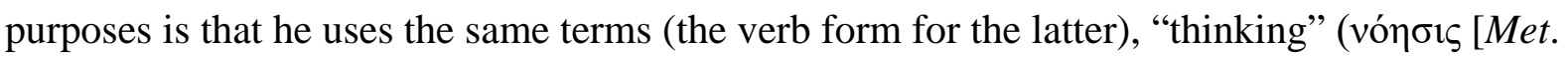
$\Theta 9,1051 \mathrm{a} 30])$ and “making” ( $\pi 010 \tilde{v} \tau \varepsilon \varsigma[$ [Met. $\Theta 9,1051 \mathrm{a} 31-32])$, in the $\Theta 9$ passage in

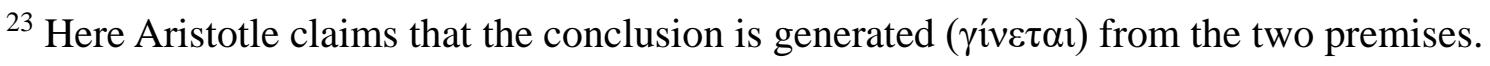


question. This may well indicate that by using those words for geometrical proofs he has in mind the same contrast there, between the process of analysis and that of synthesis. As I shall discuss in detail below, indeed, "thinking” at 1051a30 is concerned with the analytic process of bringing a given geometrical proposition back to the one by means of which it is proved (Met. $\Theta 9,1051 \mathrm{a} 29-30$ ), and “making” at 1051a31-32 with the synthetic process of actually proving the given proposition from that prior proposition (Met. $\Theta 9,1051 \mathrm{a} 31)$. This procedural contrast, especially the link of the word 'thinking' (vónбıs) to an analytic or regressive process, has been neglected in the literature, but constitutes good evidence for my GA interpretation.

Now, in the light of the preparatory discussion so far, I will elucidate in order what, on this GA interpretation, each portion of the $\Theta 9$ passage means one by one. The opening remark is that "it is by actuality that $\tau \grave{\alpha} \delta 1 \alpha \gamma \rho \alpha ́ \mu \mu \alpha \tau \alpha$ are also discovered” (Met. $\Theta 9$, 1051a21-22). It follows from my above observation that $\tau \grave{\alpha} \delta 1 \alpha \gamma \rho \alpha ́ \mu \mu \alpha \tau \alpha$ mean geometrical proofs. Aristotle is here suggesting that, in addition to the other arguments in chapter 8 , the priority of actuality can also be confirmed by looking at how we discover geometrical proofs. The ensuing passage is therefore to explain how. He starts by saying "for it is by division that people discover them” (Met. $\Theta 9,1051 \mathrm{a} 22-23)$. The sentence means, on my GA interpretation, that geometrical analysis plays an essential role in discovering the proofs of geometrical propositions. Dividing geometrical proofs is equivalent to identifying those premises by means of which the given propositions are proved. This is why Aristotle continues, "If they had been already divided, they would have been obvious; but as it is they are present only potentially” (Met. $\Theta 9,1051 \mathrm{a} 23-24)$. Once the relevant premises of geometrical propositions are identified by analysis, it is straightforward to construct their proofs. ${ }^{24}$ But until then, the geometrical proofs remain unrevealed-more literarily, they are

\footnotetext{
${ }^{24}$ Cf. SE 16, 175a23-28, where Aristotle says that in arguments, even though a point is obvious, if one lacks practice, one often misses the chance to point it out, and that likewise, even though one analyzes the geometrical proofs ( $\tau \grave{\alpha} \delta 1 \alpha \gamma \rho \alpha ́ \mu \mu \alpha \tau \alpha$ ), one is sometimes unable to synthesize ( $\sigma v v \theta \varepsilon \tilde{v} v \alpha$ ) them in turn. The idea here is that once the premises of a
} 


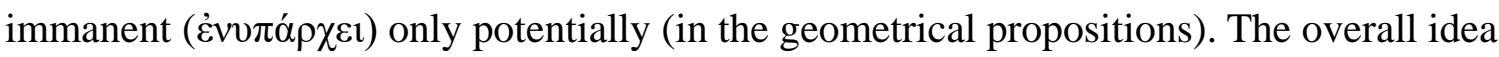
here that naturally emerges from my GA interpretation of diving $\tau \grave{\alpha} \delta 1 \alpha \gamma \rho \alpha ́ \mu \mu \alpha \tau \alpha$ is thus that a geometrical proposition is potential or actual, depending on whether or not it has been proved from its premises, the identification of which involves an analytic or regressive process of division.

Then Aristotle gives us the two geometrical examples at 1051a24-29. I have already criticized the GC interpreters' view that he treats division here as the process of constructing geometrical figures like drawing a parallel line and joining points. What is said at 1051a26, 28-9 to become clear after the process of division is not the geometrical construction itself but the cause of, or reason for ( $\delta i \grave{\alpha} \tau i$ [Met. $\Theta 9,1051 \mathrm{a} 24,26])$, the truth of the geometrical propositions. His focus is clearly placed on their proofs. The operation of adding auxiliary lines to the given figures is illustrated not for the sake of making the necessary constructions apparent, but for the sake of disclosing the arrangement of those prior propositions by means of which the given propositions are proved. ${ }^{25}$ In addition, I noted above that the two examples are deliberately related to each other, especially in the way in which the first proposition is used as a premise to prove the second. His suggestion at 1051a28-29 would therefore be that one needs to know the first proposition beforehand in order to have the

geometrical proposition are analytically identified, it should be obvious how to construct its synthetic proof, which nicely matches his description of the role of division here. See also MA 7, 701a7-13, where Aristotle claims that when one thinks the two premises, one thinks and synthesizes the conclusion.

${ }^{25}$ Malink says that by dividing a figure in a suitable manner an inquirer reveals not only the construction but also the premises needed to give a proof of the proposition ("Aristotle on Principles as Elements,” 205-7). I think he is right in drawing proper attention to the aspect of disclosing the premises of the proposition. But, like other GC interpreters, he treats the process of division itself as constructing a figure and therefore does not explain Aristotle's main point about the potentiality-actuality relation in geometry by reference to the relation between the two geometrical propositions in question. 
successful analysis of the proof of the second. This conveys the idea that analysis of a geometrical proof is effected by identifying the prior proposition one has already proved to be true and which serves as a premise of the proof. ${ }^{26}$

Next, the discussion leads to clarification of Aristotle's main theme that actuality is

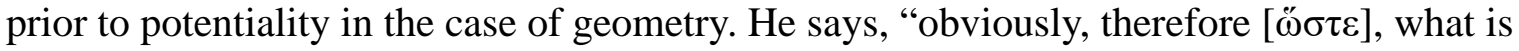
potential is discovered by being brought to actuality, the reason being that thinking is an

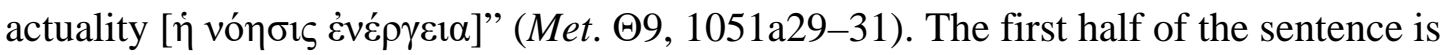
introduced as a consequence of his preceding illustrations of how the proof of a geometrical proposition is discovered. I therefore suggest that the actuality to which a potential proposition is brought should not be its own actual state (which is posterior in generation, as he points out at 1051a32-33) but rather the prior proposition by means of which it is proved, and which has already been proved. ${ }^{27}$ The concrete examples above were thus aimed at

${ }^{26}$ The same idea cannot be applied to the first proposition itself, which Aristotle apparently considers to be proved by reference to the indemonstrable principle that a straight angle is two right angles (cf. Phys. II.9, 200a15-30, VIII.1, 252b2-4; and DA I.1, 402b16-22). At Met. B6, 1002b32-1003a5 (cf. Met. B1, 996a10-11) Aristotle asks the question whether the elements or first principles are potential or actual. And he takes up the virtually same question again at Met. $\Lambda 6,1071 \mathrm{~b} 22-26$, where he has just expressed his view that there must be such a

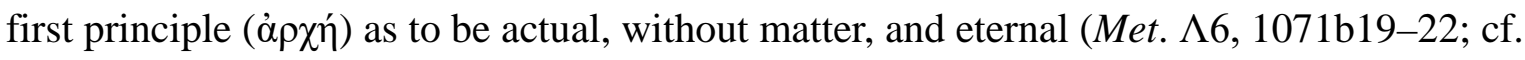
$\Theta 8,1049 \mathrm{~b} 26-27)$. Although he does not discuss geometry here, we can speculate by analogy that he considers the geometrical propositions that express indemonstrable first principles of geometry to be actual without proofs, not composed of any other propositions. Likewise, the corresponding geometrical facts can be thought to be constituted by no more basic facts. But it is beyond the scope of this paper to discuss the issue in detail.

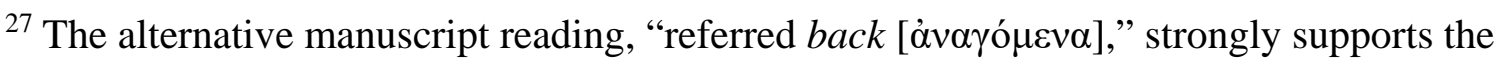
basic idea of my GA interpretation. The word is often used when what are referred back to are first principles. There are plenty of Aristotelian examples: with regard to the Metaphysics, for example, see A9, 992a10; a2, 994b17; Г2, 1004a1, b34; Г3, 1005b32; E3, 1027b14; Z11, 
showing that the proof of the second geometrical proposition is discovered by being referred to the first one. My construal of this key passage is therefore substantially different from the GC interpreters' construal of it as meaning that the potential construction is discovered by being brought to the actual construction. The second half ("the reason being that thinking is an actuality”) is laconic but can be fleshed out along the same lines. We have seen above that Aristotle identifies the process of analysis in productive knowledge, which proceeds from the end to be achieved to its means, as that of 'thinking' (Met. Z7, 1032b15-17; cf. DA III.10, 433a13-17). His use of the term 'thinking' here may well indicate that he has the same analogy between analysis in productive knowledge and that in geometry in mind as he discusses in the above Nicomachean Ethics passage. If so, the point will be that the actuality of thinking in geometry means completing the process of geometrical analysis, namely identifying the relevant premise by means of which the given proposition is proved. The second clause thus gives an account of the first clause in the sense that referring the given proposition back to its premise is the completion of the process of geometrical analysis.

The final part of the passage is the following: "so that potentiality is from actuality, and therefore it is by making that people acquire the knowledge, for the individual actuality is later in generation” (Met. $\Theta 9,1051 \mathrm{a} 31-33)$. The discussion so far naturally leads to the

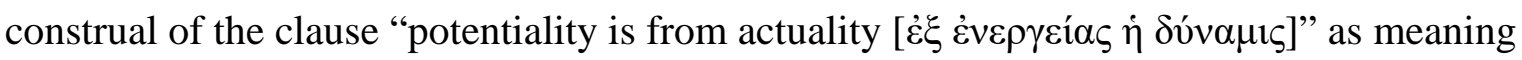
that a potential geometrical proposition derives from, or is proved by means of, its premise, namely the prior proposition that has already been proved. It has been disputed whether we should supply the clause with the verb from the preceding sentence "discovered"

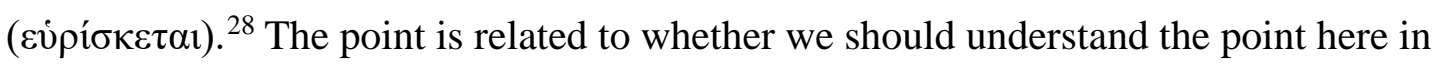

1036b12; Z16, 1040b20-21; H3, 1044a13; and K3, 1061a13, 16, b14. Ross rejects this reading because the operation of referring back is that of the philosopher, not of the mathematician (Aristotle's Metaphysics, 2:272). But his claim presupposes that the operation in question is geometrical construction. There is no reason why a mathematician should not refer a proposition back to its premises for its proof.

${ }^{28}$ Ross is against the supplement in view of the close connection of this passage to the 
connection to his discussion at $\Theta 8,1049 \mathrm{~b} 17-29$, where he argues that a man derives from the child, who in turn derives from his father. (If we supply the verb, the connection will be tenuous.) But it seems to me that Aristotle's contrast of the actuality in question with "the

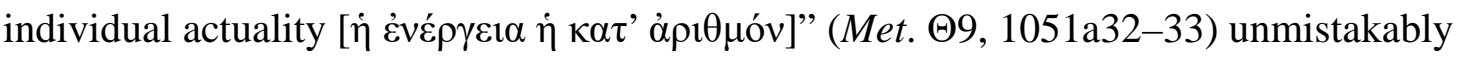
indicates that there is a close similarity in structure between the two passages, in which the contrasted items are numerically different but under the same class (cf. Met. Z8, 1033b2932). This squares with my above reading of the clause as not supplying the verb “discovered," according to which the contrast is between two geometrical propositions one of which derives from the other. If that is correct, then Aristotle here seems to be shifting his focus from the process of analysis to that of synthesis, which nicely matches the rest of the sentence: “and therefore it is by making [ $\pi$ oเoṽv $\tau \varepsilon \varsigma]$ that people acquire the knowledge, for the individual actuality is later in generation.” In the light of the analogy to productive knowledge we saw above, by “making” Aristotle is likely to mean producing a synthetic

discussion at Met. $\Theta 8,1049 b 17-29$ (Aristotle’s Metaphysics, 2:272). On the other hand, Makin is for the supplement because he says that the general rule at $\Theta 8,1049 b 24-25$, "from

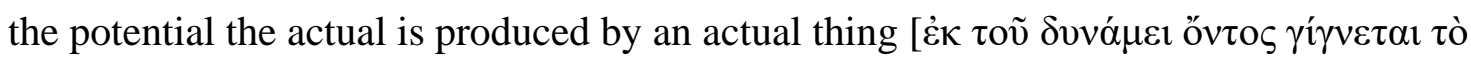

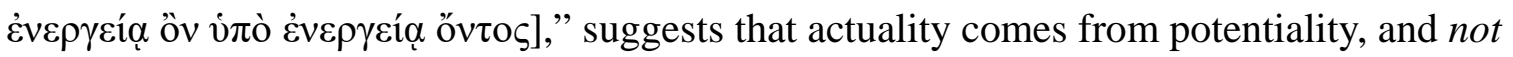
vice versa, and therefore that our present passage should not be connected too closely to the discussion there (Metaphysics Book $\Theta$, 241-42). But Makin’s claim is unwarranted because just before mentioning that general rule Aristotle says, "prior in time to them [ $\tau$ ov́ $\tau \omega v]$ there are others in actuality, from which [ $\dot{\varepsilon} \xi \tilde{\omega} v]$ they came to be” (Met. $\Theta 8,1049 b 23-24)$, and the referent of $\tau o v ́ \tau \omega v$ is surely such potentially existing things as matter, seed and so on.

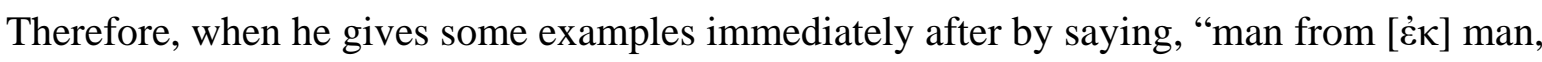
musician by [نं ó] musician” (Met. $\Theta 8,1049 b 25-26)$, by “from man” he is highly likely to mean "from (or by) an actual man” rather than "from a potential man” (cf. Ross, Aristotle’s Metaphysics, 2:260; and Tricot, La Métaphysique, 2:508n4; pace Makin, Metaphysics Book $\Theta, 186)$. This suggests that his distinction between "from” ( $\dot{\varepsilon} \kappa)$ and "by” (íó) is not so consistent. 
proof of the given proposition, knowledge of which the inquirer can thereby achieve. Only after this synthetic process does the proposition become actual because its actualization comes later than that of its premise in the order of the deductive structure of geometry.

Thus, the GA interpretation draws attention to the following three different items in the synthetic order of geometry: a potential geometrical proposition (a geometrical proposition in which its proof is immanent only potentially), its own actuality and the actual proposition from which it derives. The first item is prior to the second, but is posterior to the third. In this way Aristotle establishes his main thesis in the $\Theta 9$ passage that actuality (the third item) is prior to potentiality (the first) in geometry. If my exposition so far is on the right track, his argument about the priority of actuality in geometry is based on the asymmetrical relation between geometrical propositions in which one is proved by means of the other, and not vice versa. It is true that, since it is an inquirer who proves a geometrical proposition by referring it back to its premises, my GA interpretation is certainly concerned with an epistemic priority. But that epistemic priority is essentially different from the kind of epistemic priority the GC interpretation suggests. For the GC interpreters' claim that an inquirer's actual cognition is prior to a potential geometrical figure focuses on the relation between the inquirer and the geometrical figure. In contrast, the kind of epistemic priority based on my GA interpretation is concerned with the relation between the relevant geometrical propositions themselves. The point is that knowledge of a geometrical proposition is prior to that of a proposition that derives from it, and that an inquirer can therefore prove the latter proposition by deducing it from the former proposition.

A philosophically important implication of the GA interpretation is that it opens up a connection to ontological priority between geometrical facts. For, since each geometrical proposition represents the corresponding fact that a certain geometrical object possesses such and such a property, the derivation of a geometrical proposition from another is connected to, or rather grounded in, the asymmetrical relation between the corresponding geometrical facts. It is true that our $\Theta 9$ passage is full of epistemological terms such as discovery (Met. $\Theta 9$, 1051a21-22, 23, 30), knowledge (Met. $\Theta 9,1051 \mathrm{a} 29,32)$, thinking (Met. $\Theta 9,1051 \mathrm{a} 30)$ and clear recognition (Met. $\Theta 9,1051 \mathrm{a} 23,26,28)$. One might therefore object that, even if my GA 
interpretation is correct, its point should nevertheless be limited to the alternative epistemic priority it reveals. But we can see that the priority of a geometrical proposition to another is ultimately based on the corresponding ontological priority, by considering the following basics of Aristotle’s theory of scientific knowledge ( $\dot{\varepsilon} \pi \imath \tau \eta \dot{\mu \eta})$ and demonstration

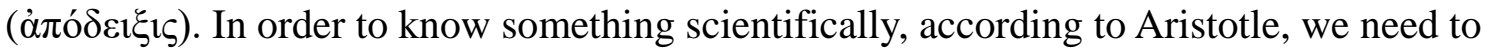

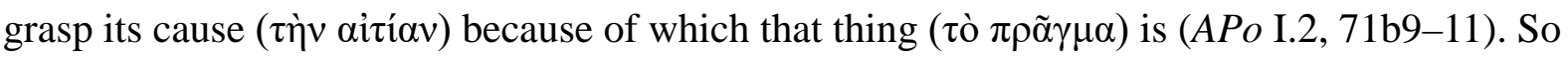
when he says that the premises of a demonstration are causes of the conclusion (APo I.2, 71b19-22, 29-33), he should mean that the facts corresponding to the premises are causes of the fact corresponding to the conclusion (cf. APo I.13, II.16). And he presents this causal feature of demonstration as more basic than, or explanatory of, the point that the premises are prior to the conclusion (APo I.2, 71b31). The link of the priority claim to the causal one is important because two propositions are often logically equivalent, namely provable from each other, especially in mathematics. In fact, he elsewhere remarks, "of things which reciprocate as to implication of being, that which is in some way the cause of the other's being might reasonably be called prior by nature" (Cat. 12, 14b11-13). Although he goes on to give as an example the relation between a statement and its corresponding fact there, there is no reason why the remark should not apply to the equivalent relation between two geometrical propositions. For example, the more basic proposition that the triangle has the sum of its internal angles equal to two right angles can also be logically deduced from the more complex proposition that the angle in the semicircle is a right angle. But Aristotle would not admit that this deductive inference is a proof yielding to scientific knowledge, because the latter fact is not the cause of the former. And he explicitly denies the possibility of circular

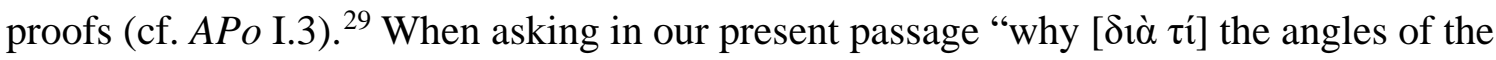
triangle are equal to two right angles" (Met. $\Theta 9,1051 \mathrm{a} 24)$ and "why the angle in a semicircle

\footnotetext{
${ }^{29}$ He seems to even deny (APo II.17, 18) that there are different proofs of the same conclusion. Even if he does not (cf. APo I.29), this should not mean the admission of circular proofs; but it may entail the idea that, ontologically, one and the same fact can be analyzed into different sets and arrangements of more basic facts.
} 
is right” (Met. $\Theta 9,1051 \mathrm{a} 26-7)$, therefore, Aristotle is highly likely to be asking about the causes because of which those geometrical facts obtain. Indeed, he surely thinks that the latter fact is grounded in the former fact, which is, in turn, grounded in what he probably considers as a first principles of geometry, that a straight angle is two right angles (Phys. II.9, 200a1530, VIII.1, 252b2-4; DA I.1, 402b16-22), although Euclid demonstrates it (Elements, I.13). What an inquirer does by dividing geometrical proofs is to discover such an ontological connection between the corresponding geometrical facts that exists independently of his or her mind. For this reason, the epistemic priority I am arguing Aristotle endorses reveals his implicit commitment to the ontological priority between geometrical facts.

However, then, what kind of ontological relation could Aristotle have in mind? And if geometrical facts are not susceptible to any change, how is the potentiality-actuality distinction ascribable to them? We can find a hint at the questions by looking at a parallel passage, Posterior Analytics II.11, 94a20-35, where he suggests that the topical propositions involve material causation. The matter-substance schema is not explicit in our present passage, but will turn out to be a plausible background of the discussion, as I shall discuss below, in the light of the wider context of the second half of Metaphysics Book $\Theta$. In the next section I explore how Aristotle ascribes material causation to the relationship between geometrical facts, and how that ascription could square with his belief that they do not involve change.

\section{Material Causation in Geometry}

In Posterior Analytics II.8-10 Aristotle argues that the essence of a thing that has its cause different from itself can be revealed, but not demonstrated, by use of a syllogistic demonstration in which the middle term is the cause of the thing. Since there are different kinds of cause, he devotes the following chapter, II.11, to showing how each kind of cause plays the part of the middle term in a demonstration. Before discussing formal, efficient and final cause, he starts with the cause formulated as "if what things hold, it is necessary that this 


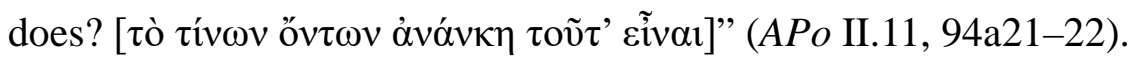

$<\mathrm{ext}>$

The case in which if something holds it is necessary that this does, does not occur if one premise is assumed, but only if at least two are; and this occurs when they have one middle term. So when this one thing is assumed it is necessary for the conclusion to hold. It is clear too as follows: Why is the angle in the semicircle right? It is right if what holds? Well, let right be $A$; half of two rights $B$; the angle in the semicircle $C$. Thus $B$ is the cause of why $A$, right, belongs to $C$, the angle in the semicircle. For this is equal to $A$ and $C$ to $B$; for it is half of two rights. So if $B$, half of two rights, holds, then $A$ belongs to $C$ (that is, the angle in the semicircle is right). And what it is to be it is the same as this, since this is what its account signifies. (APo II.11, 94a24-35, trans. modified)

$</$ ext $>$

There should be no doubt that Aristotle here has in mind the same geometrical propositions as he discusses at Metaphysics $\Theta 9,1051 \mathrm{a} 21-33$ : the proposition that the angle in the semicircle is a right angle (hereafter 'the R proposition'), and the proposition that the triangle has the sum of its internal angles equal to two right angles (hereafter 'the $2 \mathrm{R}$ proposition'). ${ }^{30}$ The $\mathrm{R}$ proposition, as we saw above, is proved by means of the $2 \mathrm{R}$ proposition, which is therefore most probably the referent of the middle term. One might wonder, however, that what he literally designates as the middle term, "half of two rights," does not really correspond to the exact content of the $2 \mathrm{R}$ proposition. But this should not be problematized, because he elsewhere notices that it is difficult to reduce to a syllogistic form those arguments that contain complicated phrases and ideas, like the proof of the 2R proposition (APr I.35). The implication would be that such complex arguments, typically geometrical proofs, often have to be overly compressed when transformed into syllogisms. No wonder, then, that the actual phrase used here for the middle term contains only a part of the $2 \mathrm{R}$ proposition, "two rights,"

\footnotetext{
${ }^{30}$ See Mendell, “Two Geometrical Examples,” who meticulously shows that the two passages use the same geometrical examples and proofs.
} 
and also the process of proof that appeals to the point that the angle in the semicircle is "half of” the sum of the internal angles of the triangle (see fig. 2). Since the cause in question is something that necessitates the truth of the R proposition, it should mainly refer to the $2 \mathrm{R}$ proposition.

In view of the fact that Aristotle presents the cause in this section as one of the four types of cause, the other three of which are formal, efficient and final cause, it is highly likely that he intends it to be a material cause. ${ }^{31}$ Although he does not use the term 'matter' ( $\tilde{\lambda} \lambda \eta$ ) or such a cognate expression as "that out of which a thing comes to be and which is immanent in

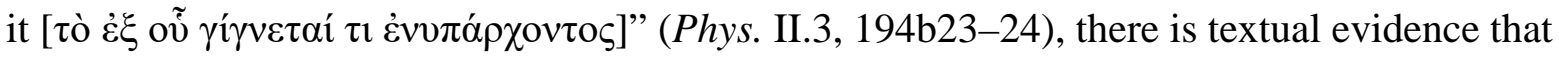
at least some propositions count as material causes.

$<\mathrm{ext}>$

All the causes now mentioned fall into four familiar divisions. The letters are the causes of syllables, the material of artificial products, fire and the like of bodies, the parts of the whole, and the hypotheses of the conclusion, in the sense of "that from which.” Of these pairs the one set are causes in the sense of what underlies, e.g. the parts, the other set in the sense of essence - the whole and the combination and the form. (Phys. II.3, 195a15-21, trans. modified; cf. Met. $\Delta 2$, 1013b16-23)

$</$ ext $>$

The set of examples here indicate that Aristotle regards hypotheses as the material causes of their conclusion. By "hypotheses” he should not mean syllogistic premises in general, ${ }^{32}$ but

${ }^{31}$ Ross, Aristotle’s Prior and Posterior Analytics, 638-40, followed by E. S. Forster and Hugh Tredennick, Posterior Analytics; Topics, 208-10, denies the identification of the cause in question with the material cause. But his interpretation, I think, has been rightly rejected by Barnes, Aristotle’s Posterior Analytics, 226. Both ancient commentators, Themistius, Paraphrasis, 52, 1-11, and Philoponus, Commentaria, 375, 25-377, 13, explicitly take the cause to be material.

${ }^{32}$ It is hardly likely that any syllogistic premises, regardless of their content, are regarded as 
the more specific ones that serve as the ultimate grounds of each science for its synthetic structure of demonstrations. He normally counts hypotheses among the indemonstrable first principles of a science, for example, the assumption about a straight line in the case of geometry (Phys. II.9, 200a15-30, VIII.1, 252b2-4; DA I.1, 402b16-22), ${ }^{33}$ but occasionally ascribes the status to fundamental but demonstrable propositions as well, such as the $2 \mathrm{R}$ proposition (EE II.6, 1222b23-41, II.11, 1227b25-32). We have also seen above that he calls those primary demonstrations 'elements' of demonstrations, which are constituents of, and immanent in, the ones posterior to them (Met. $\Delta 3,1014 \mathrm{a} 26-\mathrm{b} 3)$. All this textual evidence suggests that in the cited Analytics passage Aristotle does treat the 2R proposition as the material cause of the R proposition. It is true that his discussion of necessity here does not apply to typical material causes: in natural and artificial productions matter does not necessarily attain to its form, for example, a pile of bricks can fail to become a house (cf. Phys. II.9, 200a15-30). But that fact does not mean that the present geometrical case is not concerned with material cause. Aristotle’s strategy may rather be to deliberately pick out, among others, the kind of material cause that necessarily brings about the conclusion, in order to make the case that every type of cause, including material one, can play the part of the

material causes (cf. Wolfgang Detel, Analytica posteriora, 2:702-3). Aristotle notices at APo I.13, 78a28-b11 that, even if a proposition is inferable from another, the fact specified in the latter is not always the cause of the fact specified in the former (cf. APo II.16). In addition, he elsewhere says that hypotheses are the origin of demonstrations (Met. $\Delta 1,1013 a 15-17)$, which I think suggests that they are the origin of only the kind of syllogism that brings about knowledge. For the relationship between hypotheses and demonstrations, see APo I.2, 71b16-72a24 (cf. Met. E1, 1025b3-18). For a more extensive discussion of the issue, see Malink, “Aristotle on Principles as Elements.”

${ }^{33}$ Ross, Aristotle’s Metaphysics, 2:199-200, and Mueller, “Aristotle on Geometrical Objects," 163-9, suggest that in the Metaphysics those hypotheses that form the foundation for geometry are identified as “intelligible matter.” Cf. Met. Z10, 1036a9-12; Z11, 1037a2-5; and H6, 1045a33-36. 
middle term in a demonstration.

But why, then, does Aristotle think that the premises of a scientific demonstration constitute the material causes of the conclusion? Since whether a syllogism is a scientific demonstration depends on whether the facts stated in its premises are the causes of the fact stated in the conclusion, the ontological relation between the corresponding facts seems to be the key to determining whether the causes in question are material causes. It is beyond the scope of this paper, however, to explore the question in relation to other scientific disciplines. But we can see how at least geometrical facts involve material causation. For example, the fact specified in the $2 \mathrm{R}$ proposition (hereafter 'the $2 \mathrm{R}$ fact') materially composes the fact specified in the R proposition (hereafter 'the R fact'). As you see from the structure of the proof exhibited in fig. 2, the R fact can be seen as a certain arrangement of, or decomposed into, the 2R fact and some other auxiliary facts, the former of which Aristotle specifically treats as the cause. The $2 \mathrm{R}$ fact is thus a constitutive part of the $\mathrm{R}$ fact (cf. APo I.1, 71a1921). What underlies the scientific demonstration of the $\mathrm{R}$ proposition from the $2 \mathrm{R}$ proposition is therefore the grounding relation in which the $2 \mathrm{R}$ fact materially composes the $\mathrm{R}$ fact. My point, however, is not that more complex geometrical objects (for example, the semicircle relevant to the $\mathrm{R}$ fact) can be decomposed into more basic ones (for example, the inscribed triangle and rest relevant to the $2 \mathrm{R}$ fact). For the same cannot be said about the derivation of the $2 \mathrm{R}$ proposition from the first principle that a straight angle is two right angles. As you see in fig. 1, the triangle does not have as its constitutive part that straight line the angle of which is two right angles, but the straight line in question is something added to it. (This is clearer in Euclid's famous proof of the Pythagorean theorem at Elements, I.47, where Euclid adds a square to each side of the triangle. The triangle itself does not have the squares as its constitutive parts, of course.) Still, we can say that the 2R fact is a certain arrangement of, or decomposed into, the fact that a straight angle is two right angles and some other auxiliary facts. In geometry, thus, the more basic facts stated in the premises of a demonstration constitute the material causes of the fact stated in the conclusion.

I have argued above that Aristotle’s argument at Metaphysics $\Theta 9,1051 \mathrm{a} 21-33$ centers on the idea that an inquirer "divides" the proof of a geometrical proposition (for example, the 
R proposition) to identify its constitutive proposition serving as its premise (for example, the $2 \mathrm{R}$ proposition). It is hard to believe that this talk of division was motivated by the mere fact that the $2 \mathrm{R}$ proposition is used for, or a part of, the proof of the R proposition just as it plays the part of the middle term in the demonstrative syllogism. A real possibility we can see from the parallel Analytics passage is that the $\Theta 9$ argument reflects his implicit appeal to the same assumption that the $2 \mathrm{R}$ fact serves as the material cause of the $\mathrm{R}$ fact. The $2 \mathrm{R}$ fact composes the $\mathrm{R}$ fact, but that composition is not immediately clear, so that an inquirer makes it apparent by dividing or decomposing the constitution of the $\mathrm{R}$ fact with the help of the geometrical (auxiliary) construction (cf. Met. H4, 1044a23-25). The point of the constructions illustrated at 1051a24-29 should therefore be revealing the arrangement of the constitutive facts of which the fact to be proved is composed. I should emphasize again that this sense of division is essentially different from what the GC interpreters claim, namely constructing a geometrical figure by drawing a line and so on.

One might wonder that since matter corresponds to potentiality and substance or form to actuality, on this view, potentiality may turn out to be prior to actuality, which contradicts his main thesis at the $\Theta 9$ passage. But the $2 \mathrm{R}$ fact being the matter of the $\mathrm{R}$ fact does not necessarily entail that contradictory consequence. For the $2 \mathrm{R}$ fact is also an enformed compound or actuality of the facts prior to it. In the synthetic order of geometry, therefore, the $2 \mathrm{R}$ fact as compound or actuality comes before the $2 \mathrm{R}$ fact as matter or potentiality is actualized as the R fact as compound or actuality, which certainly establishes the priority of actuality to potentiality. This ontological version is exactly parallel to the above epistemological point of my GA interpretation, that the $2 \mathrm{R}$ proposition is proved and becomes actual before the potential R proposition is proved and becomes actual. There is, to be sure, an apparent difference between the two cases in that, while in the epistemological case the potentiality in question is the potential R proposition, in the ontological case it is the $2 \mathrm{R}$ fact as matter. But Aristotle makes it clear at $\Theta 7$, especially 1049a18-24, that what is potentially in a form is identical with its proximate matter; for example, what is potentially a casket made of wood is identical with the wood as its proximate matter. Since what is potentially the $\mathrm{R}$ fact is therefore the same as the $2 \mathrm{R}$ fact as its proximate matter, there is no substantial 
difference between the above ontological and epistemological cases. The difference is only in perspective due to the epistemological focus of the $\Theta 9$ passage on the analysis of geometrical proofs. But this should not deny the possibility that, under the surface of the passage, Aristotle has in mind the corresponding ontological relation between geometrical facts.

Still, one may reasonably doubt that ontological priority in geometry could really be a point of the $\Theta 9$ passage in any sense, because it is not clear how that potentiality-actuality distinction is attributable to geometrical facts that Aristotle thinks are not susceptible to change (cf. Met. A8, 989b32-33 and so on). To clear up this final doubt I need to draw attention to the wider context of Book $\Theta$ where the present passage is situated. In Metaphysics $\Theta$ Aristotle starts his discussion of potentiality by focusing on what he calls its

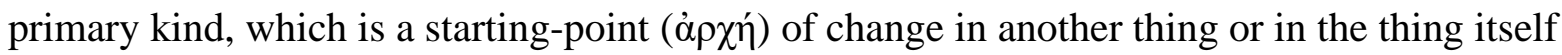
qua other. But he notices that this is only preliminary to the main subject because the relation between potentiality and actuality does not always involve, but goes beyond the domain of, change (Met. $\Theta 1,1045 b 35-1046 a 2$; cf. $\Theta 3,1047 a 30-31)$. At the beginning of chapter 6 , he announces that he will extend his discussion, as promised at the outset, by drawing attention to a further use of potentiality whose actuality is different from change (Met. $\Theta 6,1048 a 25-$ 30). Thus, he introduces that new potentiality-actuality relation that turns out to be, or at least include, the relation between matter and substance (or form) (Met. $\Theta 6,1048 b 6-9)$. This sounds rather strange, however, if we think of the fact that the process in which matter acquires its form normally involves change, for example, the process in which bricks and timber become a house. (In Phys. I.7, in fact, Aristotle introduces the matter-form distinction specifically to explain change.) Here we cannot go into such a controversial issue about different kinds of actuality—change, substance and activity—as to require a detailed discussion of the whole structure of Book $\Theta$. So I draw on the explanation of the key transition here offered by Michael Frede, whose interpretation has widely been accepted in the successive literature: that Aristotle's renewed point in chapter 6 is to use the relation between the builder's ability to build a house (potentiality) and the transitional process of building it (change/actuality) to explain the relation between what is potentially a house 
(matter/potentiality) and what is actually it (substance or form/actuality). ${ }^{34}$ His main aim in Book $\Theta$ is thus to clarify such different modes of being from the beginning (cf. Met. $\Theta 1$, 1045b27-35).

An important consequence of Aristotle's expansion of discussion in chapter 6 is that he is now entitled to use the matter-substance distinction to analyze an actually existing object as well. At Metaphysics $\Theta 7,1049 a 18-24$ he thus points out that the matter composing an enformed compound is potentially that compound; for example, the wood composing a casket is potentially the casket. His point should not simply be that wood was potentially a casket before it was turned into it, but more generally that it is potentially the casket even when it composes it now. ${ }^{35}$ This analysis of an actual compound into its matter and form indeed plays an important role in his discussion of the unity of a compound in H6, where he claims that if its elements are matter and form, it is obvious for it to be unified because the proximate matter and the form are one and the same thing, the former potentially and the latter actually (Met. H6, 1045b17-19; cf. 1045a20-33). It is often pointed out in the literature that his analysis here is exploiting the fact that, when composing a compound, the constitutive or proximate matter preserves those dispositional properties it needs to possess to be suitable for composing that compound. ${ }^{36}$ For example, bricks and timber do not lose their dispositional property of hardness even after they are turned into a house (cf. DA II.5,

${ }^{34}$ Frede, “Notion of Potentiality,” especially 182-4, offers this interpretation of the transition from the first half of Book $\Theta$ to the second, which has been widely accepted in the literature (cf. Jonathan Beere, Doing and Being, 19-29, 169-71; and Makin, Metaphysics Book $\Theta$, 1821, 133-34). Andreas Anagnostopoulos does not accept this point of the transition but still concedes that Book $\Theta$ is concerned with the philosophical innovation of linking potentiality to a mode of being (“Senses of Dynamis," especially 404-5).

35 See Beere, Doing and Being, 269-70; and Makin, Metaphysics Book $\Theta$, 167-68.

36 J. L. Ackrill, “Psuche,” 124-27; Frede, “Notion of Potentiality,” 191-92; Cynthia A. Freeland, “Aristotle on Bodies, Matter, and Potentiality,” 396-98, 404-6; L. A. Kosman, “Substance, Being, and Energeia,” 131-34; and Makin, Metaphysics Book $\Theta$, 168-74. 
417a21-b7). The idea should therefore be that the matter composing a compound preserves its potentiality to be it and keeps that potentiality constantly actualized as long as the compound the matter composes continues to exist actually. What is significant here for our purposes is that this view of his would not necessarily require the matter composing a compound to have been turned into it to be qualified for being potentially it: it would be enough that it actually composes that compound now, whether or not it was turned into it. Recent scholarship has in fact shown, although not concerned with a matter-substance relation, that the point of Aristotle's discussion of such eternal objects as the celestial bodies at Metaphysics $\Theta 8,1050 \mathrm{~b} 6-28$ is that they are eternally in motion because they necessarily or seamlessly exercise their relevant potentiality. ${ }^{37}$ Against the common reading of the passage that their eternal motion is not a result of any potentiality, this renewed interpretation gives additional support for my claim that geometrical facts do not need to have existed potentially before to exist actually.

Having contextualized our $\Theta 9$ passage in this way, I submit, we can now see little reason why Aristotle could not ascribe the distinction between potentiality as matter and actuality as substance or form to unchanging geometrical facts. Rather, the GA interpretation I have thus far argued for nicely fits into his main theme of Book $\Theta$, which comes to the fore in chapter 6 . The issue was that a geometrical fact cannot metaphysically undergo any temporal process from potentiality to actuality: the process in which a geometrical fact derives from another is instantaneous. For example, if the $2 \mathrm{R}$ fact is the case or actual, then the $\mathrm{R}$ fact is simultaneously the case or actual. It is not that the $2 \mathrm{R}$ fact becomes actual temporally before it actualizes the $\mathrm{R}$ fact by composing it, but that the $\mathrm{R}$ fact is always present actually, composed by the $2 \mathrm{R}$ fact, as long as the $2 \mathrm{R}$ fact exists actually, composed by the still prior fact. It therefore follows that all geometrical facts, whether or not we have discovered the proofs of the corresponding propositions, already exist actually, and that there are no geometrical facts that exist potentially now and come to exist actually later.

\footnotetext{
${ }^{37}$ See Christopher Frey, “Capacities and the Eternal;” and Lindsay Judson, “Aristotle, Metaphysics $\Theta .8,1050 \mathrm{~b} 6-28 . ”$
} 
Nevertheless, as we have seen, this does not mean that geometrical facts have nothing to do with potentialities or actualization: the point is that their actual existence is the result of the perpetual actualization of the corresponding potentialities - their switches are always on. For example, the $\mathrm{R}$ fact is an incessant actuality of what is potentially the $\mathrm{R}$ fact, namely the $2 \mathrm{R}$ fact as its proximate matter, which is in turn an incessant actuality of what is potentially the $2 \mathrm{R}$ fact, namely the nature of a straight line. This ontological picture is a natural consequence of the idea exhibited in the $\Theta 9$ passage, that all geometrical propositions, excluding the indemonstrable first principles, have the proposition(s) synthetically prior to them as their constitutive parts. Aristotle does not think that geometrical facts are not independent of each other, but that they are interrelated in the asymmetrical and hierarchical structure in which every geometrical fact ontologically depends on the fact prior to it and in turn provides the ontological ground in the fact posterior to it. This could be the view underlying his argument about the priority of actuality to potentiality in geometry in the $\Theta 9$ passage.

\section{Conclusion}

To wrap up this paper, I would like to add a brief discussion of what kind of ontological priority, then, Aristotle considers geometrical facts to involve, in comparison with his discussion of the priority of actuality in substance at Metaphysics $\Theta 8,1050$ a4-16 among others. The point there is that what is posterior in generation (for example, a house) is prior in form and substance to what is prior in generation (for example, its matter). (For the sake of simplicity I shall focus here on the matter-substance (form) example, mentioned at 1050a1516.) Scholars have different views of Aristotelian ontological priority. Some think that $x$ is ontologically prior to $y$ just in case $x$ can exist without $y$, but not vice versa. ${ }^{38}$ Others think

\footnotetext{
38 John J. Cleary, Senses of Priority, 48-51; Gail Fine, “Separation;” Makin, Metaphysics Book $\Theta$, 192-96; and Christos Y. Panayides, "Priority of Actuality.”
} 
that $x$ is ontologically prior to $y$ just in case $x$ can be what it is without $y$, but not vice versa. ${ }^{39}$ These two are major views, although they are not the only available options in the literature. ${ }^{40}$ The aim of the present discussion of geometry is not, of course, to settle this fierce interpretative controversy, but just to provide an additional material that has not been considered in the debate. As far as the $\Theta 8$ passage is concerned, the existential reading has proved difficult. This is because matter or potentiality can exist without the form it acquires or actuality, and not vice versa, and the priority is therefore the other way around. ${ }^{41}$ The essentialist reading seems to be the better option at least here than any other: what it is to be matter certainly depends on the form it acquires, but not vice versa. For matter is for the sake

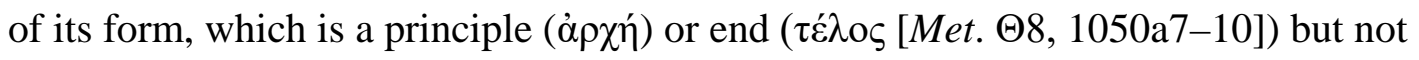
conversely.

The same can be said about our geometrical case in which the $2 \mathrm{R}$ fact is ontologically prior to the $\mathrm{R}$ fact. The existential reading cannot explain the fact that if the $2 \mathrm{R}$ fact is the case, the $\mathrm{R}$ fact is the case. For this is equivalent to the claim that if the $\mathrm{R}$ fact is not the case, the $2 \mathrm{R}$ is not the case, which denies that the prior item can exist without the posterior item. The essentialist reading, on the other hand, gives a plausible account of Aristotle's point. For it is because the sum of the internal angles of the triangle is two right angles that the angle in

\footnotetext{
${ }^{39}$ Michail Peramatzis, Priority in Aristotle’s Metaphysics, Part II, especially Chapter 8; and Lynne Spellman, Substance and Separation in Aristotle, 86. Cf. Kit Fine, “Ontological Dependence.” Beere, Doing and Being, 293-304, and Malink, “Essence and Being,” 353-60, take the middle position that Aristotle sometimes presents ontological priority as existential, and sometimes as essentialist.
}

${ }^{40}$ For example, Donald Morrison argues that $x$ is ontologically independent of $y$ just in case $x$ is outside of the boundaries of $y$ ("Separation in Aristotle’s Metaphysics”). Phil Corkum argues that $x$ is ontologically independent of $y$ just in case $x$ admits of the ontological status of a being independently of standing in some tie to $y$ ("Aristotle on Ontological Dependence”).

${ }^{41}$ For a detailed discussion, see Peramatzis, Priority in Aristotle’s Metaphysics, 278-86. 
the semicircle is a right angle, but not vice versa. The $2 \mathrm{R}$ fact thus plays the role of fixing the identity of the R fact, and not conversely. This is so despite the fact that there is mutual implication between the 2R fact's being the case and the $\mathrm{R}$ fact's being the case. Aristotle makes the same point at EE II.6, 1222b29-37, where he says that if the triangle has its angles equal to two right angles, the quadrilateral has its angles equal to four right angles (the $4 \mathrm{R}$ fact), but that if the triangle had its angles equal to three right angles, the quadrilateral would have its angles equal to six right angles. The relation between the two facts is supposed to be

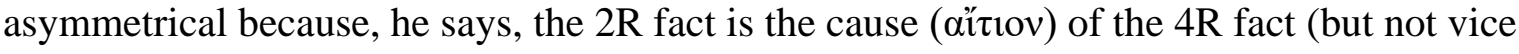
versa). This causal account nicely fits my earlier suggestion that the $2 \mathrm{R}$ proposition is supposed to be prior to the R proposition because the corresponding $2 \mathrm{R}$ fact is the cause of the corresponding R fact (cf. Cat. 12, 14b11-13). The 2R fact is ontologically prior to the $\mathrm{R}$ fact because the former causally determines the identity of the latter, but not conversely. Thus, the priority of actuality in geometry exhibited in $\Theta 9$ involves the same, essentialist kind of ontological priority as the priority of actuality in substance in $\Theta 8$, especially the mattersubstance example at 1050a15-16. ${ }^{42}$

However, these two parallel cases of ontological priority have some differences as well. One is that, since the $\Theta 8$ formulation-what is posterior in generation ( $\gamma \varepsilon v \varepsilon ́ \sigma \varepsilon \imath$ ) is prior in form and substance-presupposes that matter changes to attain to its form, this cannot apply, strictly speaking, to the unchanging geometrical facts. But Aristotle points out in the above parallel passage that we can treat them by analogy as having the same relations as changing objects (EE II.6, 1222b23-37). This analogy in the present geometrical case can be best shown, as he did in $\Theta 9$, by focusing on the corresponding geometrical propositions. For by drawing attention to the order in which an inquirer derives one from another by proof, we can easily think of them analogously as being generated (Met. $\Theta 9,1051 \mathrm{a} 32-33)$. Such an epistemic aspect of priority in geometry is parallel to the priority in formula ( $\lambda$ ó $\gamma \omega)$ in $\Theta 8$, 1049b12-17, which is an epistemic counterpart of priority in substance. But another, more

\footnotetext{
${ }^{42}$ Cf. Peramatzis, Priority in Aristotle's Metaphysics, 238-43, who discusses the essentialist view of ontological priority in connection to a causal relation.
} 
important difference is that, while matter in $\Theta 8$ (for example, bricks and stones) is ontologically posterior to what it composes (for example, a house), matter in geometry (for example, the $2 \mathrm{R}$ fact) is ontologically prior to what it composes (for example, the $\mathrm{R}$ fact). This discrepancy is due to the opposite direction of necessity discussed in Physics II.9, 200a15-30, where Aristotle argues that, while the principle in production is a form (for example, the form of house) that necessitates the kind of matter appropriate for its end (hypothetical necessity), the principle in geometry is a more basic fact (for example, the $2 \mathrm{R}$ fact) that necessitates its consequences (for example, the $\mathrm{R}$ fact). But he avoids this apparent priority of matter or potentiality, as I showed above, by appealing to the point that the $2 \mathrm{R}$ fact is also the actuality of the corresponding matter or potentiality, namely the nature of a straight line. The solution adopted here is rather analogous to the case of priority in time in which parents are prior to their children (Met. $\Theta 8,1049 b 23-27)$.

All the discussion so far leads to my final conclusion that the priority of actuality in geometry in $\Theta 9$ is best taken as an appendix to Aristotle’s overall argument for the priory of actuality in $\Theta 8$, especially priority in substance. I agree with some commentators that $\Theta 9$ should be treated as a folder, which means that the material collected there is only loosely integrated with that in $\Theta 8 .^{43}$ (I also share the assumption that the evaluative priority of actuality discussed in the first half of $\Theta 9$ is not fitted into any argument in $\Theta 8$ or tied with our present case of geometry.) But this is by no means to say that his discussion of geometrical potentialities in the folder is of less philosophical interest than the main thread of argument in $\Theta 8 .^{44}$

${ }^{43}$ Cf. Makin, Metaphysics Book $\Theta, 221$.

44 This paper originates in my work for Anna Marmodoro’s research project "Power Structuralism in Ancient Ontologies,” funded by the European Research Council. I am grateful to her and her project members for their support. I would also like to thank Victor Caston, Tamer Nawar, Michail Peramatzis, David Sedley, and the anonymous referees for their valuable written comments. In addition, the paper has benefitted from the feedback given by audiences at the 76th Annual Conference of the Philosophical Association of Japan 
Bibliography and Abbreviations

Ackrill, J. L. “Aristotle’s Definitions of 'Psuche.” Proceedings of the Aristotelian Society 73 (1972): 119-33. [“Psuche”]

Anagnostopoulos, Andreas. "Senses of Dynamis and the Structure of Aristotle's Metaphysics

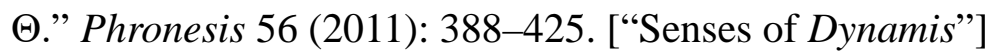

Annas, Julia. Aristotle’s Metaphysics: Books M and N. Oxford: Clarendon Press, 1976.

[Books $M$ and $N]$

Aristotle. Analytica priora et posteriora. Edited by W. D. Ross and L. Minio-Paluello. Oxford: Clarendon Press, 1964. [APr, APo]

—. De anima. Edited by W. D. Ross. Oxford: Clarendon Press, 1961. [DA]

—. De caelo. Edited by W. C. K. Guthrie. Cambridge: Harvard University Press, 1939. $[D C]$

—. Categoriae et liber de interpretatione. Edited by L. Minio-Paluello. Oxford:

Clarendon Press, 1949. [Cat.]

—. The Complete Works of Aristotle: The Revised Oxford Translation, 2 vols. Edited by Jonathan Barnes. Princeton: Princeton University Press, 1984. [Complete Works]

—. Ethica Eudemia. Edited by J. M. Mingay and R. R. Walzer. Oxford: Clarendon Press, 1991. [EE]

—. Ethica Nicomachea. Edited by I. Bywater. Oxford: Clarendon Press, 1894. [EN]

—. Metaphysica. Edited by Werner Jaeger. Oxford: Clarendon Press, 1957. [Met.]

—. Meteorologicorum libri quattuor. Edited by F. H. Fobes. Cambridge, MA: Harvard University Press, 1919. [Metr.]

—. De motu animalium. Edited by Martha Craven Nussbaum. Princeton: Princeton

(Tokyo, 2017) and Ancient Philosophy Mini-conference (Oxford, 2018). Lastly, I appreciate the following financial support for completing the work: the Overseas Research Fellowship from the Japan Society for the Promotion of Science and the Postdoctoral Fellowship from the British Academy. 
University Press. [MA]

—. Physica. Edited by W. D. Ross. Oxford: Clarendon Press, 1950. [Phys.]

—. Politica. Edited by W. D. Ross. Oxford: Clarendon Press, 1957. [Pol.]

—. Topica et sophistici elenchi. Edited by W. D. Ross. Oxford: Clarendon Press, 1958. [Top., SE]

Barnes, Jonathan. Aristotle’s Posterior Analytics. Oxford: Clarendon Press, 1975.

Bechler, Z. Aristotle's Theory of Actuality. Albany: State University of New York Press, 1995.

Beere, Jonathan. Doing and Being: An Interpretation of Aristotle’s Metaphysics Theta. Oxford: Oxford University Press, 2009. [Doing and Being]

Behboud, Ali. “Greek Geometrical Analysis.” Centaurus 37 (1994): 52-86.

Bonitz, Hermann. Index Aristotelicus. Berlin: G. Reimer, 1870.

Burnyeat, Myles, et al. Notes on Books Eta and Theta of Aristotle's Metaphysics. Oxford: Sub-faculty of Philosophy University of Oxford, 1984. [Notes on Eta and Theta] Cleary, John J. Aristotle on the Many Senses of Priority. Carbondale: Southern Illinois University Press, 1988. [Senses of Priority]

Corkum, Phil. “Aristotle on Mathematical Truth.” British Journal for the History of Philosophy 20 (2012): 1057-76.

__. “Aristotle on Ontological Dependence.” Phronesis 53 (2008): 65-92.

Detel, Wolfgang. Analytica posteriora, 2 vols. Berlin: Akademie Verlag, 1993.

Euclid. Elementa, libri I-IV. In Euclidis opera omnia, vol. 1. Edited by I. L. Heiberg and H. Menge. Leipzig: Teubner, 1883. [Elements]

Fine, Gail. “Separation.” Oxford Studies in Ancient Philosophy 2 (1984): 31-87.

Fine, Kit. “Ontological Dependence.” Proceedings of the Aristotelian Society 95 (1995): 26990.

Forster, E. S., and Hugh Tredennick. Posterior Analytics; Topics. Cambridge: Harvard University Press, 1960.

Frede, Michael. “Aristotle's Notion of Potentiality in Metaphysics $\Theta . ”$ In Unity, Identity, and Explanation in Aristotle’s Metaphysics, edited by Theodore Scaltsas, David Charles, 
and Mary Louise Gill, 173-93. Oxford: Oxford University Press, 1994. [“Notion of Potentiality"]

Freeland, Cynthia A. “Aristotle on Bodies, Matter, and Potentiality.” In Philosophical Issues in Aristotle’s Biology, edited by Allan Gotthelf and James G. Lennox, 392-407. Cambridge: Cambridge University Press, 1987.

Frey, Christopher. “Capacities and the Eternal in Metaphysics $\Theta .8$ and De Caelo.” Phronesis 60 (2015): 88-126. [“Capacities and the Eternal”]

Gulley, Norman. “Greek Geometrical Analysis.” Phronesis 3 (1958): 1-14.

Hasper, P. S. "Being Clear about the Explanation: A Mathematical Example in Aristotle, Metaphysica $\Theta .9$, 1051A26-9.” The Classical Quarterly 61 (2011): 172-77.

[“Explanation”]

Heath, Thomas. Mathematics in Aristotle. Oxford: Clarendon Press, 1949.

Hintikka, Jaakko, and Unto Remes. The Method of Analysis: Its Geometrical Origin and its General Significance. Dordrecht: Reidel, 1974. [The Method of Analysis]

Judson, Lindsay. “Aristotle, Metaphysics $\Theta .8$, 1050b6-28.” Phronesis 61 (2016): 142-59.

Knorr, Wilbur Richard. The Evolution of the Euclidean Elements. Dordrecht: D. Reidel, 1975.

Kosman, L. A. “Substance, Being, and Energeia.” Oxford Studies in Ancient Philosophy 2 (1984): 121-49.

Lear, Jonathan. “Aristotle’s Philosophy of Mathematics.” The Philosophical Review 91 (1982): 161-92.

Makin, Stephen. Metaphysics Book $\Theta$. Oxford: Clarendon Press, 2006.

Malink, Marko. “Aristotle on Principles as Elements.” Oxford Studies in Ancient Philosophy 53 (2017): 163-213.

__. "Essence and Being.” Oxford Studies in Ancient Philosophy 45 (2013): 341-62.

Mendell, Henry. “Two Geometrical Examples from Aristotle’s Metaphysics.” The Classical Quarterly 34 (1984): 359-72. [“Two Geometrical Examples”]

Morrison, Donald. "Separation in Aristotle's Metaphysics.” Oxford Studies in Ancient Philosophy 3 (1985): 125-57. 
Mueller, Ian. “Aristotle on Geometrical Objects.” Archiv für Geschichte der Philosophie 52 (1970): 156-71.

Netz, Reviel. The Shaping of Deduction in Greek Mathematics: A Study in Cognitive History. Cambridge: Cambridge University Press, 1999. [The Shaping of Deduction]

Panayides, Christos Y. “Aristotle on the Priority of Actuality in Substance.” Ancient philosophy 19 (1999): 327-44. [“Priority of Actuality”]

Pappus of Alexandria. Collectionis quae supersunt, vol. 2. Edited by Frederick Hultsch. Berlin: Weidmann, 1877. [Collection]

Peramatzis, Michail. Priority in Aristotle's Metaphysics. Oxford: Oxford University Press, 2011.

Philoponus. In Aristotelis analytica posteriora commentaria cum anonymo in librum II. In Commentaria in Aristotelem Graeca 13.2. Edited by M. Wallies. Berlin: Reimer, 1909. [Commentaria]

Ross, W. D. Aristotle’s Metaphysics, 2 vols. Oxford: Clarendon Press, 1924. Aristotle’s Prior and Posterior Analytics. Oxford: Clarendon Press, 1949.

Saito, Ken, and Nathan Sidoli. “The Function of Diorism in Ancient Greek Analysis.” Historia Mathematica 37 (2010): 579-614. [“The Function of Diorism”]

Spellman, Lynne. Substance and Separation in Aristotle. Cambridge: Cambridge University Press, 1995.

Themistius. Analyticorum posteriorum paraphrasis. In Commentaria in Aristotelem Graeca 5.1. Edited by M. Wallies. Berlin: Reimer, 1900. [Paraphrasis]

Tricot, J. La Métaphysique, New ed., 2 vols. Paris: J. Vrin, 1964. 